\title{
Formation of a Copper(II)-Tyrosyl Complex at the Active Site of Lytic Polysaccharide Monooxygenases Following Oxidation by $\mathrm{H}_{2} \mathrm{O}_{2}$
}

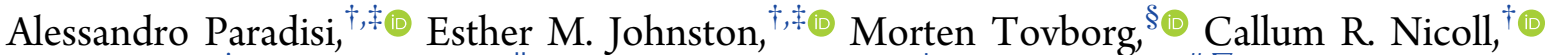 \\ Luisa Ciano, ${ }^{\dagger \odot}$ Adam Dowle, ${ }^{\| \odot}$ Jonathan McMaster, $^{\perp \odot}$ Y. Hancock, ${ }^{\#, \nabla \odot ~ G i d e o n ~ J . ~ D a v i e s, ~}{ }^{*}, \dagger \odot$ \\ and Paul H. Walton* ${ }^{* \dagger}$ \\ ${ }^{\dagger}$ Department of Chemistry, "Centre of Excellence of Mass Spectrometry, Technology Facility, and "Department of Physics, \\ University of York, Heslington, York YO10 5DD, United Kingdom \\ ${ }^{\S}$ Novozymes A/S, Krogshoejvej 36, 2880 Bagsvaerd, Denmark \\ ${ }^{\perp}$ School of Chemistry, University of Nottingham, University Park, Nottingham NG7 2RD, United Kingdom \\ ${ }^{\nabla}$ York Cross-Disciplinary Centre for Systems Analysis, University of York, Heslington, York YO10 5GE, United Kingdom
}

\section{Supporting Information}

ABSTRACT: Hydrogen peroxide is a cosubstrate for the oxidative cleavage of saccharidic substrates by copper-containing lytic polysaccharide monooxygenases (LPMOs). The rate of reaction of LPMOs with hydrogen peroxide is high, but it is accompanied by rapid inactivation of the enzymes, presumably through protein oxidation. Herein, we use UVvis, $\mathrm{CD}$, XAS, EPR, VT/VH-MCD, and resonance Raman spectroscopies, augmented with mass spectrometry and DFT calculations, to show that the product of reaction of an AA9 LPMO with $\mathrm{H}_{2} \mathrm{O}_{2}$ at higher $\mathrm{pHs}$ is a singlet $\mathrm{Cu}(\mathrm{II})$-tyrosyl radical species, which is inactive for the oxidation of saccharidic substrates. The $\mathrm{Cu}(\mathrm{II})$-tyrosyl radical center entails the formation of significant $\mathrm{Cu}(\mathrm{II})-\left({ }^{\bullet} \mathrm{OTyr}\right)$ overlap, which in turn requires that the plane of the $\mathrm{d}\left(x^{2}-y^{2}\right)$ SOMO of the $\mathrm{Cu}(\mathrm{II})$ is orientated toward the tyrosyl radical. We propose from the Marcus cross-relation that the

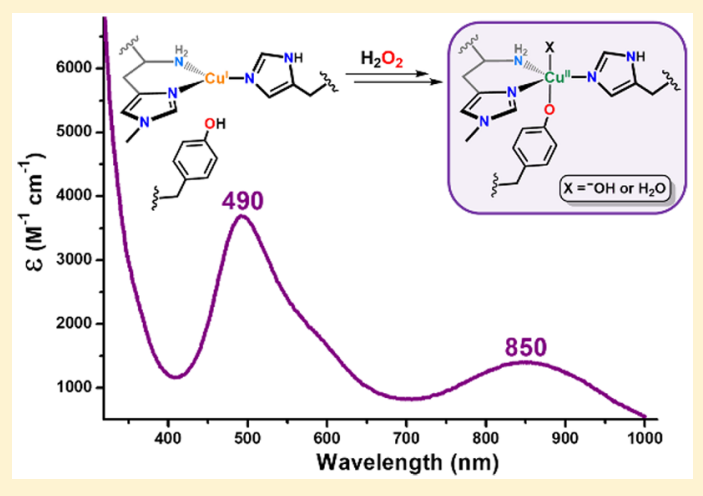
active site tyrosine is part of a "hole-hopping" charge-transfer mechanism formed of a pathway of conserved tyrosine and tryptophan residues, which can protect the protein active site from inactivation during uncoupled turnover.

\section{INTRODUCTION}

Lytic polysaccharide monooxygenases (LPMOs, also known as PMOs) are copper-containing enzymes that catalyze the oxidative cleavage of polysaccharides by dioxygen or hydrogen peroxide. ${ }^{1}$ The active site of LPMOs contains a single copper ion coordinated by an $\mathrm{N}$-terminal histidine through the $\mathrm{NH}_{2}$ of the amino terminus and the $\pi$ - $\mathrm{N}$ of its imidazole side chain. ${ }^{2} \mathrm{~A}$ $\mathrm{T}$-shaped coordination geometry at the $\mathrm{Cu}$ is completed by the $\tau$ - $\mathrm{N}$ atom of a further histidine side chain. This structural unit is known as the histidine brace ${ }^{3}$ (Scheme 1). There is interest in LPMOs, not only for their use in commercial bioethanol production $^{4}$ and bacterial/fungal virulence ${ }^{5}$ but also for theas yet unknown-details of their catalytic mechanism(s), ${ }^{6}$ especially the means by which the enzyme oxidizes a $\mathrm{C}-\mathrm{H}$ bond in the polysaccharide substrate, the bond dissociation energy (BDE) of which is calculated to be ca. $100 \mathrm{kcal} / \mathrm{mol}^{7}$

Studies of LPMOs have concentrated on the active site, with more recent attention focusing on the role of amino acid residues within the secondary coordination sphere of the $\mathrm{Cu}$ center. ${ }^{8}$ Here the situation is complicated by the fact that LPMOs exist in at least seven distinct phylogenetic groups (listed as classes AA9, AA10, ${ }^{1 \mathrm{~b}}$ AA11, ${ }^{9}$ AA13, ${ }^{10}$ AA14, ${ }^{11}$ $\mathrm{AA}_{15}{ }^{12}$ and $\mathrm{AA}^{16} 6^{13}$ in the CAZy database). ${ }^{14}$ Each class
Scheme 1. Active Site Structure of a Cu(II)-AA9 LPMO, Depicting the Histidine Brace, a Noncoordinated Tyrosine, and Axially-Positioned and Equatorially-Ligated Water Molecule $^{a}$

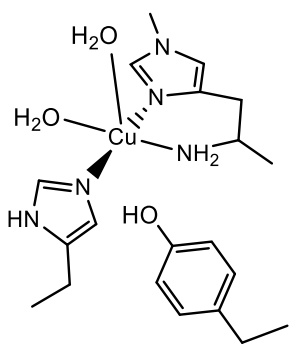

${ }^{a} \mathrm{Cu}-\mathrm{O}$ (axial water) distance is $>2.6 \mathrm{~A}$, too long to be considered a significant bonding interaction.

presents a subtly different active site structure, due to differences in the identities and positions of amino acid

Received: September 16, 2019

Published: November 1, 2019 
Scheme 2. Known Active Site Structures of LPMO, Classified According to the CAZy Database, Showing Conserved Residues in the Active Site ${ }^{a}$
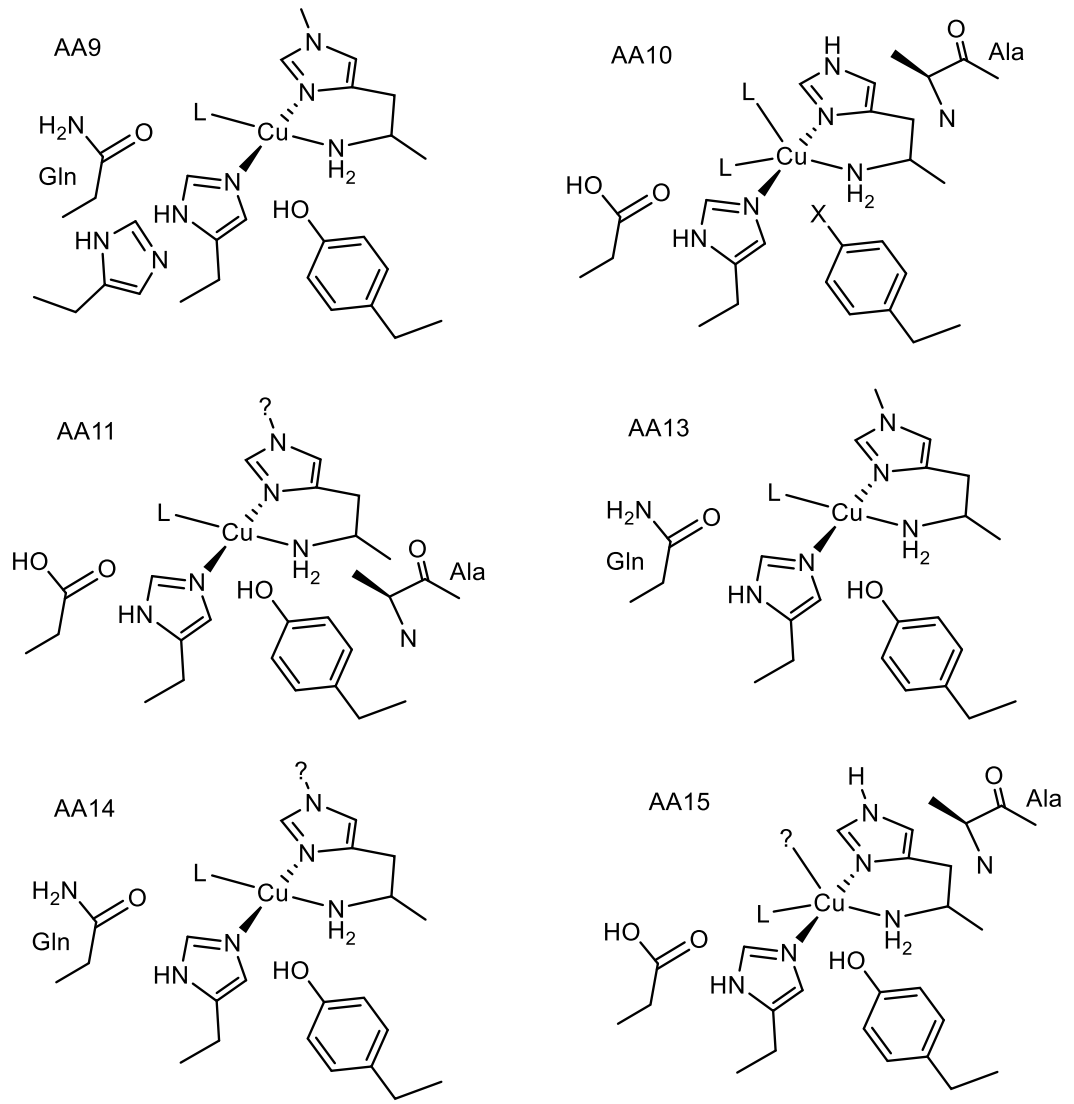

${ }^{a} \mathrm{~L}$ refers to exogenous ligands, usually $\mathrm{H}_{2} \mathrm{O} / \mathrm{OH}^{-}$or $\mathrm{Cl}^{-}$. Wild-type AA11 and AA14 LPMOs may contain a methylated $\mathrm{N}$-terminal histidine side chain (depicted as '?'), like AA9, but this is unknown as the production systems (E. coli or Pichia pastoris) used to produce these enzymes lack the necessary enzymatic methylation apparatus (the AA16 class is not included in the scheme, as no structure is yet available).

residues in the secondary coordination sphere of the copper (Scheme 2). ${ }^{15}$

The secondary coordination sphere of the copper ion in proteins can have profound effects on the reactivity of any exogenous ligands bound to the copper. ${ }^{16}$ Indeed, in the context of LPMOs, ongoing site-directed mutagenesis work coupled with activity studies and EPR spectroscopic measurements have highlighted the critical role, in terms of catalytic activity, of the glutamine in the active site of AA9 LPMOs and the important roles of a tyrosine and noncoordinating histidine that are also found in the secondary coordination sphere. ${ }^{8,17}$ Also, the significance of an alanine side chain in AA10 LPMOs has recently been demonstrated, in which the methyl group of the alanine likely restricts coordination of exogenous ligands in the axial position of the copper coordination sphere. ${ }^{18}$ Among these residues, however, the role of the tyrosine found in all LPMO classes (except some AA10 LPMOs) and which is always positioned in the axial coordination position of the copper ion has attracted the most attention, not least because it is not clear how this side chain is not oxidized in preference to the substrate during catalytic turnover; $\mathrm{BDE}(\mathrm{O}-\mathrm{H})$, ca. 88 $\mathrm{kcal} / \mathrm{mol}^{19}$

In this regard, various proposals exist for the role of the tyrosine in the mechanism of LPMOs. Principal among these is that the tyrosine forms part of an electron transfer chain that delivers electrons from an exogenous reducing agent to the copper while the LPMO is in contact with a substrate. ${ }^{10 a}$
There have also been proposals where the tyrosine/tyrosyl radical redox couple stabilizes an intermediate $\mathrm{Cu}$ (II)-oxyl or $\mathrm{Cu}(\mathrm{III})-\mathrm{OH}$ species, similar to the formation of the porphyrin radical cation seen in Compound I of P450 enzymes. ${ }^{20} \mathrm{~A}$ further proposal is that the tyrosine protects LPMOs from selfoxidation during the nonsubstrate-coupled turnover of $\mathrm{O}_{2}{ }^{21}$ this suggestion parallels a similar role for tyrosine(s) in P450 enzymes. ${ }^{22}$ In delineating a role for the tyrosine in LPMOs, however, direct experimental evidence is scarce. There have been no spectroscopic determinations of any intermediates, save for a single report from Singh et al., who observe tyrosyl radical formation upon treatment of a $\mathrm{Cu}(\mathrm{II})-\mathrm{LPMO}$ with hydrogen peroxide in the presence of excess reducing agent. Using perpendicular-mode EPR, resonance Raman, and UVvis spectroscopies, the authors of this study proposed the formation of a $S=1 \mathrm{Cu}(\mathrm{II})-\left({ }^{\bullet} \mathrm{OTyr}\right)$ ferromagnetically coupled pair, which was further suggested to be part of the catalytic cycle of LPMOs. ${ }^{21,23}$ In addition to experimental work, DFT and QM/MM calculations have also been undertaken on several different LPMO systems in the presence of substrate. None of the preferred pathways from these calculations invokes a role for the tyrosine residue within the catalytic mechanism. ${ }^{24}$

It is in this context that we report a multispectroscopic (EPR, VT/VH-MCD, CD, UV-vis, XAS, resonance Raman), mass spectrometry, and DFT study into a purple-colored species that arises during the uncoupled turnover ${ }^{24 c, 25}$ of an 
AA9 LPMO with hydrogen peroxide at raised pHs. We show that this species is a stable $\mathrm{Cu}(\mathrm{II})$-tyrosyl radical, akin to those seen in other copper oxidases like galactose oxidase. ${ }^{26}$ In contrast to galactose oxidases, this tyrosine radical is not covalently modified nor is it part of the catalytic cycle of LPMOs. Moreover, at physiological $\mathrm{pHs}(<7)$ the purple species does not form to any significant extent, leading to the proposal that the active site tyrosine in LPMOs, along with a nearby tryptophan residue, is part of a hole-hopping pathway which protects LPMOs from oxidation during uncoupled turnover. ${ }^{18 a, 27}$ This study also points to the challenges which highly oxidizing intermediates present to enzymatic systems and the means by which the potentially deleterious effects of these intermediates are mitigated by the protein, not only through the use of hole-hopping residues like tyrosine but also through glycosylation substitutions on the enzyme, a feature also revealed in our current study.

\section{RESULTS AND ANALYSIS}

Formation of a Purple-Colored LPMO Species, Its pH/ Substrate/Peroxide/Glycosylation Dependence, and Its Activity on (Oligo)saccharide Substrates. LPMOs catalyze the oxidation of poly(oligo)saccharide substrates with $\mathrm{O}_{2}$ and reducing agent cosubstrates (e.g., ascorbate). In addition to $\mathrm{O}_{2}$ acting as a cosubstrate, it has also recently been reported that hydrogen peroxide acts as a cosubstrate for LPMOs, replacing the combination of $\mathrm{O}_{2}$ and reducing agent, albeit in a reaction which is accompanied by significant protein degradation. ${ }^{1,28}$ Despite the fact that the reaction with peroxide is deleterious to the enzyme, the addition of peroxide to LPMOs provides for a potential laboratory "shunt" that avoids the complicating use of reducing agents within spectroscopic and activity studies. ${ }^{24 c}$ Thus, taking advantage of the peroxide shunt reaction with LPMOs, we added various concentrations of hydrogen peroxide (from 0 to $2 \mathrm{mM}$ ) to $\sim 1$ mM solutions of an AA9 LPMO from Lentinus similis (LsAA9) which had previously been spectroscopically and structurally characterized. $^{2,29}$ This AA9 LPMO is active on soluble oligosaccharide substrates, affording the opportunity to be able to perform spectroscopic studies on optically transparent solutions. The addition of hydrogen peroxide to LsAA9 was performed at room temperature $(\sim 290 \mathrm{~K})$ over a range of $\mathrm{pHs}$ and peroxide concentrations (Figure 1). The reaction was also separately performed on both naturally glycosylated LsAA9 (the enzyme was produced using Aspergillus oryzae and Pichia pastoris as expression systems, which maintain glycosylation patterns on the protein and, in the former expression system, the $\mathrm{N}_{\varepsilon}$-methylation on His 1 ) and its de- $N$-glycosylated variant, which were prepared using previously reported methods (Supporting Information). ${ }^{2}$

The resulting solutions were monitored over time by UVvis and EPR spectroscopies. In the absence of substrate and at raised $\mathrm{pHs}(>7)$, following an initial burst of bubbling (presumably $\mathrm{O}_{2}$ gas), a strongly colored purple solution formed over a period of minutes, which then appeared to be stable over a period of days. The UV-vis and CD spectra of this solution exhibit several intense bands in the visible region (Figure 1, see later for analysis). The addition of peroxide under anaerobic conditions to the $\mathrm{Cu}(\mathrm{I})$ form of LsAA9 generated the same purple species but without the initial burst of bubbling observed for the addition of hydrogen peroxide to the $\mathrm{Cu}$ (II) form of LsAA9. These observations suggest that the appearance of bubbles following the addition of hydrogen
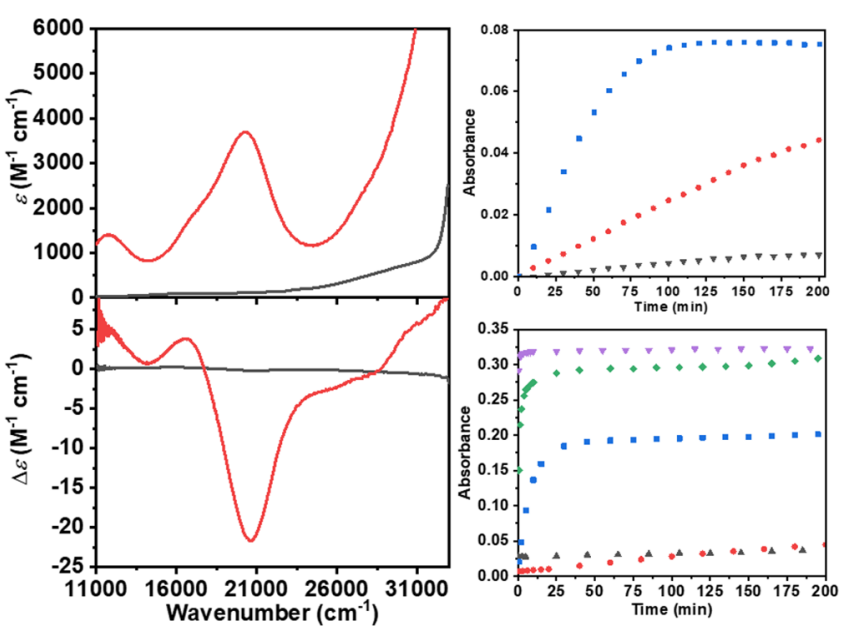

Figure 1. UV-vis (top left) and CD spectra (bottom left) of LsAA9 resting state (black) and purple species (red) at $\mathrm{pH}$ 7.0. Growth of the absorption intensity at $20400 \mathrm{~cm}^{-1}$ at different $\mathrm{H}_{2} \mathrm{O}_{2}$ concentrations (top right): $0.10 \mathrm{mM}$, black triangles; $1.0 \mathrm{mM}$, red dots; $10.0 \mathrm{mM}$, blue squares. LsAA9 $0.1 \mathrm{mM}, \mathrm{pH}$ 7.0. Growth of the absorption intensity at $20400 \mathrm{~cm}^{-1}$ at different $\mathrm{pHs}$ (bottom right): 6.0 (black triangles), 7.0 (red dots), 8.0 (blue squares), 9.0 (green diamonds), 10.0 (purple triangles). LsAA9 $0.1 \mathrm{mM}$ and $1.0 \mathrm{mM}$ $\mathrm{H}_{2} \mathrm{O}_{2}$. All kinetic studies were carried out with glycosylated enzyme (Aspergillus oryzae as expression system) at $293 \mathrm{~K}$. Maximal conversion was achieved at $\mathrm{pH} 10.0$ with an addition of $\mathrm{H}_{2} \mathrm{O}_{2} \quad 1.0$ $\mathrm{mM}$ to $0.1 \mathrm{mM}$ LsAA9 LPMO.

peroxide to the $\mathrm{Cu}$ (II) form of LsAA9 was associated with the reduction of the $\mathrm{Cu}(\mathrm{II})$ form by hydrogen peroxide and the concomitant formation of superoxide that disproportionated into $\mathrm{O}_{2}$ and hydrogen peroxide. ${ }^{30}$ The rate of formation of the purple species and its final concentration depended on the $\mathrm{pH}$ and the initial concentration of hydrogen peroxide, with high $\mathrm{pHs}$ exhibiting the highest rate of formation $\left(>0.1 \mathrm{mM} \mathrm{min}^{-1}\right)$ and highest final concentrations (Figure 1).

Once formed, the UV-vis spectrum of the purple species remained invariant across a $\mathrm{pH}$ range of 3.0-10.0 (Figure S1). At pHs lower than 3.0, the solution turned colorless with concomitant loss of the main bands (11 790, 17100,20400 $\mathrm{cm}^{-1}$ ) in the visible part of the spectrum. Addition of $\mathrm{H}_{2} \mathrm{O}_{2}$ in the presence of cellohexaose (a known oligosaccharide substrate $^{25}$ for LsAA9) gave the same purple species but at a much lower rate (ca. 200 times slower, Figure S2).

To show that the formation of the chromophore, although not necessarily its location within the protein, is associated with the copper ion, the purple species was treated with a combination of reducing agent and EDTA at $\mathrm{pH} 10.0$ as follows: the addition of sodium dithionite solution to the purple species gave a colorless and EPR-silent solution, which was then incubated with EDTA and passed through a size exclusion filter to remove the $[\mathrm{Cu}(\mathrm{EDTA})]^{2-}$ complex. The amount of $\mathrm{Cu}$ leftover in the sample was measured by $\mathrm{CW}$ EPR spectroscopy and determined by spin quantification to be less than $5 \% \mathrm{Cu}$ content with respect to the resting state enzyme at the same concentration, as shown in Figure S3 (see Methods section). Readdition of a $\mathrm{Cu}$ (II) solution to the protein solution in aerobic conditions immediately gave a purple-colored solution with the same visible spectrum as the original purple species (see Discussion for explanation of this effect). In the absence of a reducing agent it was not possible to decolorize the solution with the addition of EDTA alone, 
suggesting that the copper active site in the purple species is highly stable. In addition, we report that the same purple species could be formed under aerobic conditions at high $\mathrm{pH}$ by addition of ascorbic acid as reducing agent to the enzyme solution but at a much slower rate than the reaction with peroxide.

The ability of the purple species to catalyze the oxidation of polysaccharides with either $\mathrm{O}_{2}$ (and sodium ascorbate as the reducing agent) or hydrogen peroxide was assessed using cellohexaose as substrate. To perform these experiments it was important to remove the small amounts of LsAA9 that had not been converted to the purple species (see EPR discussion and Methods). Therefore, excess cellohexaose was added to a solution of the purple species that had previously been treated with $\mathrm{Na}_{2}$ EDTA and any $[\mathrm{Cu}(\mathrm{EDTA})]^{2-}$ removed (i.e., retaining the purple species and removing any $\mathrm{Cu}$ (II) from unreacted $\mathrm{Cu}(\mathrm{II})-L s \mathrm{AA} 9$ ). The products of the reaction, i.e., any oxidized oligosaccharides, were then analyzed by MALDITOF MS. In both cases (hydrogen peroxide or $\mathrm{O}_{2}$ /ascorbate) the purple species did not generate any oxidized oligosaccharides under standard oxidation conditions after $24 \mathrm{~h}$, and thus, the purple species appears to be catalytically inactive for the oxidation of polysaccharides (Figure S4). As a positive control, under the same conditions, LsAA9 was shown by MALDITOF MS to generate $\mathrm{C} 4$ oxidized oligosaccharide products, as already demonstrated by Frandsen et al. (Figure S4). ${ }^{2}$

SDS-PAGE gel analyses of the purple-colored solutions were performed (Figure 2) to determine whether the lack of activity of the purple species was due to indiscriminate oxidation of the protein by the peroxide. The gels show that the purple species generated from LsAA9 that had been de- $\mathrm{N}$-glycosylated indeed underwent extensive proteolytic degradation at $\mathrm{pHs}$ 7.0-8.0, even upon addition of low concentrations of hydrogen peroxide $(0.15 \mathrm{mM})$ or in the presence of substrate (cellohexaose). Such degradation is not surprising given the potent oxidizing power of hydrogen peroxide solutions. In contrast to the deglycosylated sample, LsAA9 left in its glycosylated form following its expression in Aspergillus or Pichia showed no signs of denaturation even upon treatment with a 20 -fold molar excess of hydrogen peroxide with respect to the enzyme concentration (Figure 2). The protective effect of the glycosylated side chains is evident from this experiment. Following treatment with hydrogen peroxide, glycosylated LsAA9 remained essentially intact, save for some evidence from the SDS-PAGE gels (Figure 2) of the formation of a small amount $(<1 \%)$ of a higher molecular weight species at ca. $60-$ $65 \mathrm{kDa}$. The same experiment was repeated on LsAA9 produced in Pichia pastoris as an expression system. Pichia can glycosylate but not methylate LPMOs with different glycosylation patterns/sites to Aspergillus. ${ }^{31}$ Even in this case, no peptide fragments were generated upon incubation with hydrogen peroxide (Figure S5). The finding that glycosylation protects eukaryotic LPMOs from oxidative damage by hydrogen peroxide serves as a useful reminder of the functional importance of glycosylated side chains in proteins and the need to be aware that the absence of glycosylation in AA9 LPMOs which have been expressed in prokaryotic hosts can significantly affect the stability of these proteins. Accordingly, in the studies reported below, the Aspergillus-produced, glycosylated LsAA9 was used in all spectroscopic investigations.

Sites of Oxidative Damage to the Protein Following Addition of Peroxide. The SDS-PAGE analysis described

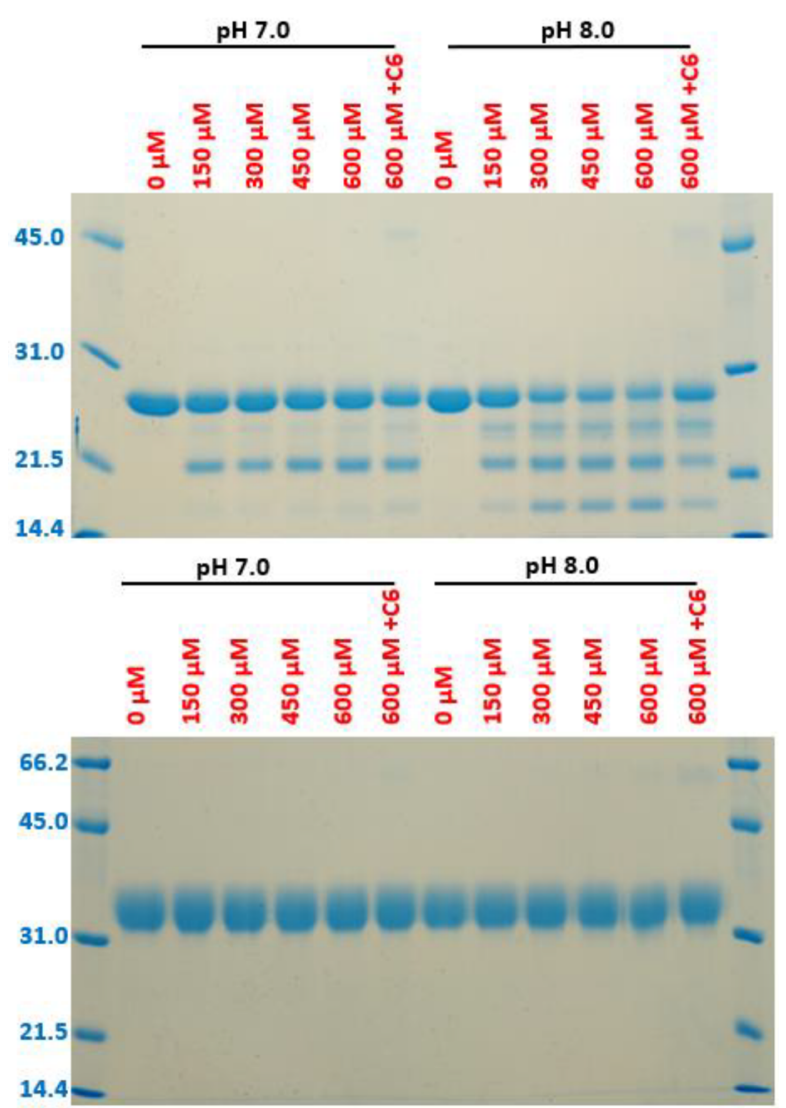

Figure 2. SDS-PAGE analysis of $\mathrm{Cu}(\mathrm{II})-L s A A 9$ LPMO before and after peroxide treatment: (top) de- $N$-glycosylated LsAA9 and (bottom) glycosylated LsAA9 (produced in Aspergillus oryzae). The reactions were performed with $30 \mu \mathrm{M} L s A A 9$ with different amounts of $\mathrm{H}_{2} \mathrm{O}_{2}$ (red labels), in $50 \mathrm{mM}$ HEPES at $\mathrm{pH} 7.0$ or $\mathrm{pH}$ 8.0. The samples were incubated for $2 \mathrm{~h}$ at room temperature before the SDSPAGE analysis. "C6" indicates the presence of $300 \mu \mathrm{M}$ cellohexaose. Molecular weight markers are reported in $\mathrm{kDa}$ (blue labels).

above does not provide detailed information about the sites of oxidative damage within the protein. In this regard, there is evidence from earlier studies that hydrogen peroxide treatment of LPMOs leads to significant oxidative damage of residues close to the copper active site. ${ }^{\text {lc }}$ Therefore, to determine the sites of oxidative damage and also to trace any potential redoxactive pathways in LsAA9, ${ }^{32}$ we performed LC-MS/MS analysis of the peroxide-treated glycosylated purple species protein post protease digestion to determine the sites of oxidative modification (Figures S6 and S7). ${ }^{33}$ This analysis was performed in two separate experiments, one employing $\mathrm{H}_{2}{ }^{16} \mathrm{O}_{2}$ and the other $\mathrm{H}_{2}{ }^{18} \mathrm{O}_{2}$ (Figures S5 and S6). The use of isotopically labeled hydrogen peroxide allowed for differentiation of peroxide treatment-induced oxidation $\left({ }^{18} \mathrm{O}\right)$ from oxidation which occurred during the protein purification procedure or sample preparation for LC-MS/MS analysis $\left({ }^{16} \mathrm{O}\right)$.

The analysis shows that the oxidative modification of amino acids by hydrogen peroxide occurred at several different sites across the protein, with measurable oxidation of some tryptophan, tyrosine, and methionine residues (Figure 3). Oxidation was also detected at other amino acid residues adjacent to the copper active site; as previously reported, ${ }^{1 \mathrm{c}}$ oxidation of the histidine 1 side chain was observed. Additional oxidative damage was seen on the active site residues His-79 


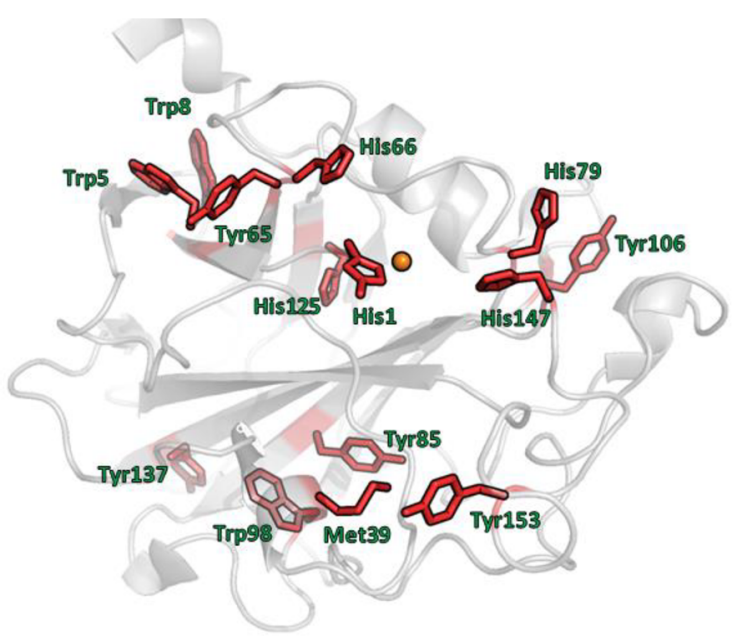

Figure 3. Ribbon view of $L s A A 9$ representing the amino acid side chains (PDB: 5ACG) where ${ }^{18} \mathrm{O}$ insertion was detected in amino acid side chains by LC-MS/MS, after treating the enzyme with $\mathrm{H}_{2}{ }^{18} \mathrm{O}_{2}$ (depicted as red cylinder bonds). The results were analyzed with PEAKSX Studio (Build 20181106, Bioinformatics Solutions Inc.) and resulting peptide matches were filtered to $1 \%$ false discovery rate in PEAKSX against a decoy database.

and His-147, commensurate with the copper-histidine brace in LPMOs being a site that generates oxidizing species. Distant from the active site, oxidative modification of Tyr-65 (12.6 $\AA$ from $\mathrm{Cu}$ ) and Trp-5 (17.6 ̊) was observed (see Discussion). Also, several other aromatic residues (Tyr-137, Tyr-153, Trp98) were oxidized; most of them are close to the enzyme surface. There was additional oxidative modification of Tyr- 85 (18.8 $\AA$ away from active site), which is notable as it forms one-half of a conserved tyrosine-dyad (Tyr-85, Tyr-191 in LsAA9) that appears in all AA9 LPMOs and, furthermore, is not surface exposed. ${ }^{27}$ Against expectations however, over all conditions there was no evidence for covalent modification of the active site tyrosine (Tyr-164). This is an important finding insofar as some copper-containing oxidases, including copper amine oxidases, are known to undergo oxidative maturation of nearby tyrosine residues into redox-active cofactors; this appears not to be the case in AA9 LPMOs. ${ }^{34}$

Spectroscopic Characterization of the Purple Species. X-ray Absorption Spectroscopy of the Purple Species. To determine the oxidation state of the copper ion in the purple species, X-ray absorption studies at $77 \mathrm{~K}$ were performed. For reference, X-ray absorption spectra were also collected on the dithionite-reduced, EPR-silent $\mathrm{Cu}(\mathrm{I})-L s A A 9$ and the $\mathrm{Cu}(\mathrm{II})$ resting state of LsAA9 (spin-Hamiltonian parameters as previously reported). ${ }^{2}$ The combination of the XAS spectra of the purple species with those of the $\mathrm{Cu}(\mathrm{I})$ and $\mathrm{Cu}$ (II) forms of LsAA9 reports on the changes at a single copper site over three oxidation levels (Figure 4).

The X-ray absorption spectrum of $\mathrm{Cu}(\mathrm{I})$-LsAA9 exhibits a characteristic XAS feature at $8982.4 \mathrm{eV}$ on the rising edge, which we assign as a $\mathrm{Cu} 1 \mathrm{~s}$ to nonbonding $4 \mathrm{p}$ transition. ${ }^{35}$ This peak is ca. $0.8-1.1 \mathrm{eV}$ lower in energy than those reported for other three-coordinate $\mathrm{Cu}(\mathrm{I})$ complexes (8983.2-8983.8 $\mathrm{eV}){ }^{35}$ The spectral profile is consistent with a $\mathrm{Cu}(\mathrm{I})$ oxidation state in which the coordination geometry at the copper is Tshaped $\mathrm{N}_{3}$. For $\mathrm{Cu}(\mathrm{II})-L s \mathrm{AA9}$, care was taken not to overexpose the sample to X-rays, which are known to photoreduce the copper from $\mathrm{Cu}(\mathrm{II})$ to $\mathrm{Cu}(\mathrm{I})$ in LPMOs;

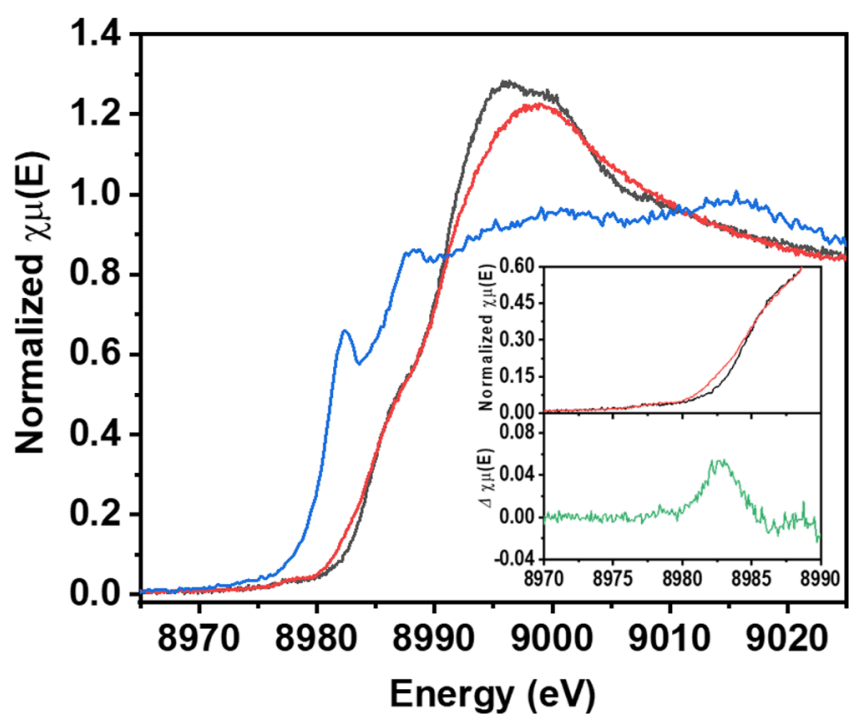

Figure 4. Normalized $\mathrm{Cu}$ K-edge XAS spectra (77 K) of purple species, $\mathrm{Cu}(\mathrm{II})$-LsAA9 (black), purple species LsAA9 (red) and reduced $\mathrm{Cu}(\mathrm{I})-L s A A 9$ (blue). In the inset, difference spectrum (green) between purple species LsAA9 and $\mathrm{Cu}(\mathrm{II})-L s A A 9$.

this was achieved by creating a raster pattern with the X-ray beam across the sample during collection. ${ }^{18 b, 36}$ Under these conditions, the subsequent XAS exhibits a weak pre-edge peak around $8977.4 \mathrm{eV}$ which results from the dipole-disallowed, quadrupole-allowed $\mathrm{Cu} 1 \mathrm{~s}$ to $3 \mathrm{~d}\left(x^{2}-y^{2}\right)$ transition. Again, as for the $\mathrm{Cu}(\mathrm{I})$ spectrum, this transition is ca. $1-1.5 \mathrm{eV}$ lower in energy than equivalent absorptions in XAS spectra of other $\mathrm{Cu}$ (II) complexes, save those of $\mathrm{Cu}$ zeolites $(8977.5 \mathrm{eV})$ used as methane oxidation catalysts ${ }^{37}$ and of distorted $\left[\mathrm{CuCl}_{4}\right]^{2-38}$ $(8977.8 \mathrm{eV})$. At higher energies a more intense band is observed on the rising edge at $8985.9 \mathrm{eV}$, which is assigned to a three-state $\mathrm{Cu} 1 \mathrm{~s}$ to $4 \mathrm{p}+\mathrm{LMCT}$ "shakedown" transition, often reported in the XAS of $\mathrm{Cu}(\mathrm{II})$ species and which typically appear in the range $8986-8988 \mathrm{eV}^{35}$ (Aside: it was recently proposed that the energy at which the "shakedown" transitions of $\mathrm{Cu}$ (II) complexes occur may be associated with ligand charge donation to the $\mathrm{Cu}$ and the amount of ligand orbital overlap with the $\mathrm{Cu} 4 \mathrm{p}$ orbitals. ${ }^{39}$ ) The pre-edge peak at $8977.4 \mathrm{eV}$ is slightly lower in energy than those reported for other $\mathrm{Cu}$ (II) complexes, indicative of some charge transfer to the $\mathrm{Cu}$ (II) center in LsAA9. This observation is in accord with the high reduction potentials $\left(>250 \mathrm{mV}\right.$ vs SHE) ${ }^{18 \mathrm{~b}}$ which are known for $\mathrm{Cu}(\mathrm{II})$ LPMOs. The position of the rising edge band at $8985.9 \mathrm{eV}$ is also commensurate with a $\mathrm{Cu}$ (II) oxidation state. ${ }^{35,40}$ Both the $\mathrm{Cu}(\mathrm{I})$ and the $\mathrm{Cu}(\mathrm{II})$ XAS closely match those found in the analogous oxidation state of another AA9 LPMO and the $\mathrm{Cu}(\mathrm{I})$ state of a AA10 LPMO reported in earlier studies. ${ }^{18 \mathrm{~b}, 30}$ Overall, the spectral features are consistent with $\mathrm{Cu}(\mathrm{I})$ and $\mathrm{Cu}(\mathrm{II})$ oxidation states of the dithionite-reduced and resting states of LsAA9 LPMO, respectively.

The XAS spectrum of the purple species in the pre-edge and rising edge regions is almost identical (peaks at 8977.8 and $8986.0 \mathrm{eV}$ ) to that of $\mathrm{Cu}(\mathrm{II})-L s \mathrm{AA} 9$. Notwithstanding the similarity, an additional weak pre-edge feature at $8982.8 \mathrm{eV}$ of similar intensity to the $8977.8 \mathrm{eV} \mathrm{Cu} 1 \mathrm{~s}$ to $3 \mathrm{~d}\left(x^{2}-y^{2}\right)$ transition is also resolved. In the difference spectrum between the purple species spectrum and $\mathrm{Cu}$ (II)-LsAA9 (inset, Figure 4), this extra peak could be cleanly fit with a single Gaussian. 

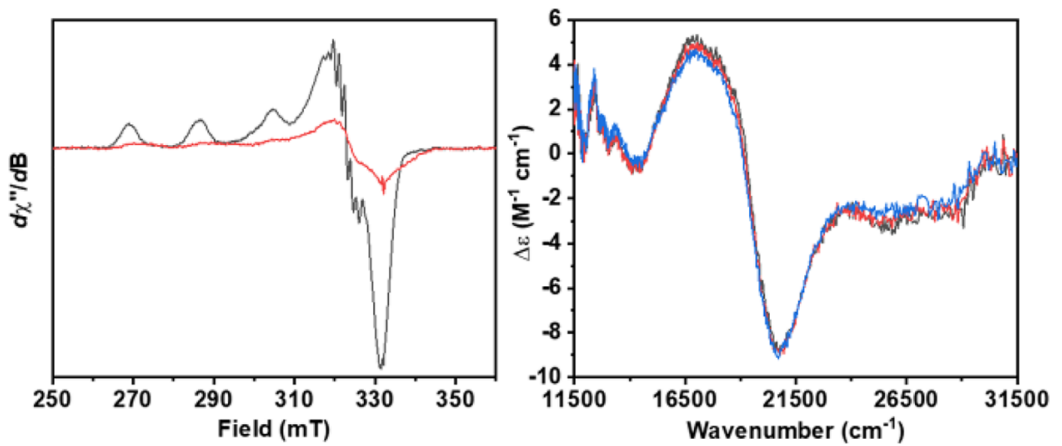

Figure 5. (Left) EPR spectra ( $160 \mathrm{~K})$ of $\mathrm{Cu}(\mathrm{II})-L s A A 9$ at $\mathrm{pH} 10.0$ (black) and of LsAA9-purple (red); in both samples the enzyme concentration was $200 \mu \mathrm{M}$, in $50 \mathrm{mM}$ CAPS pH 10.0. (Right) Field dependence of the MCD spectrum of the purple species at 3 (black), 5 (red), and $7 \mathrm{~T}$ (blue), at $5 \mathrm{~K}$. Enzyme concentration was $620 \mu \mathrm{M}, 55 \% \mathrm{v} / \mathrm{v}$ glycerol, CAPS $50 \mathrm{mM}, \mathrm{pH} 10.0$.

The difference spectrum contains no other significant features in the pre-edge and rising edge regions, showing that the preedge $1 \mathrm{~s}$ to $3 \mathrm{~d}\left(x^{2}-y^{2}\right)$ transition and the $1 \mathrm{~s}$ to $4 \mathrm{p}+\mathrm{MLCT}$ shakedown transition are essentially unaffected in intensity and energy between the two different species. Thus, given the similarity in the XAS spectra the formal oxidation state of the $\mathrm{Cu}$ center in the purple species can be assigned as $\mathrm{Cu}$ (II). A higher oxidation state assignment would require that the preedge peak is upshifted by the order of $1-2 \mathrm{eV}$.

The new peak at $8982.8 \mathrm{eV}$ in the purple species falls outside the usual window $(8986-8988 \mathrm{eV})$ of rising edge transitions, and it is also significantly shifted $(+5.0 \mathrm{eV})$ from the $\mathrm{Cu}(\mathrm{II}) 1 \mathrm{~s}$ to $3 \mathrm{~d}\left(x^{2}-y^{2}\right)$ transition, showing that it is not due to a $\mathrm{Cu}$ (III) 1 s to $3 \mathrm{~d}\left(x^{2}-y^{2}\right)$ transition. We can also rule out the possibility that this peak is due to a small amount of photoreduction, since the transition is at the wrong position $(+0.4 \mathrm{eV})$ for the $\mathrm{Cu}(\mathrm{I}) 1 \mathrm{~s}-4 \mathrm{p}$ transition and there is also no apparent drop in the intensity of the $\mathrm{Cu}(\mathrm{II}) 1 \mathrm{~s}$ to $3 \mathrm{~d}\left(x^{2}-y^{2}\right)$ peak at $8977 \mathrm{eV}$ between the purple species and $\mathrm{Cu}$ (II) LsAA9.

In summary, the positions of the shakedown transition and principal edge along with the position of the $1 \mathrm{~s}$ to $\mathrm{Cu} 3 \mathrm{~d}\left(x^{2}-\right.$ $\left.y^{2}\right)$ pre-edge feature are commensurate with a $\mathrm{Cu}(\mathrm{II})$ oxidation state (see Discussion) for both $\mathrm{Cu}$ (II)-LsAA9 and the purple species. In addition, the appearance of a new pre-edge peak at $8982.8 \mathrm{eV}$ is indicative of the formation of a new interaction between copper and a ligand (see Discussion). ${ }^{39,40}$

Optical and Magnetic Spectroscopies. Simultaneous fitting of the UV-vis and CD spectra of the purple species (Figure S8) revealed the presence of six different absorption bands at $11790\left(1400 \mathrm{M}^{-1} \mathrm{~cm}^{-1}\right), 17100\left(1800 \mathrm{M}^{-1} \mathrm{~cm}^{-1}\right), 20400$ $\left(3600 \mathrm{M}^{-1} \mathrm{~cm}^{-1}\right), 24560\left(860 \mathrm{M}^{-1} \mathrm{~cm}^{-1}\right), 28000\left(2100 \mathrm{M}^{-1}\right.$ $\left.\mathrm{cm}^{-1}\right)$, and $30810 \mathrm{~cm}^{-1}\left(3700 \mathrm{M}^{-1} \mathrm{~cm}^{-1}\right)$. These bands all grew into the $\mathrm{UV}$-vis and CD spectra at the same rate during the purple species formation, suggesting that they are all associated with a single species. This spectrum is quite different from the UV-vis absorption spectrum of LsAA9 in its resting $\mathrm{Cu}(\mathrm{II})$ state, which is characterized by a weak and broad absorption band around $16600 \mathrm{~cm}^{-1}$, typical for dipoleforbidden $\mathrm{Cu}(\mathrm{II}) \mathrm{d}-\mathrm{d}$ transitions (Figure 1). All of the visible absorption bands of the purple species disappeared upon treatment with an aqueous solution of sodium dithionite.

In generating the purple species, perpendicular-mode $\mathrm{X}$ band CW-EPR spectroscopy showed that the axial type 2 copper signal of the $\mathrm{Cu}(\mathrm{II})-L s \mathrm{AA} 9$ slowly disappeared following treatment with hydrogen peroxide to a new EPRsilent species (Figure 5). EPR spectroscopy also demonstrated that the conversion of the resting state to the purple species was not complete, even at $\mathrm{pH} 10.0$, as $15-20 \%$ of $\mathrm{Cu}$ (II) signal (as estimated by double integration of the EPR spectrum) remained following treatment of the $\mathrm{Cu}(\mathrm{II})-$ LsAA9 form with hydrogen peroxide.

The EPR-silent nature of the purple species demonstrates that it is not a Kramers' spin doublet, although it is not possible to determine from this single observation whether it is a nonKramers' singlet or triplet state. Therefore, to determine the spin state, variable-temperature, variable-field magnetic circular dichroism (MCD) spectroscopy was carried out at $\mathrm{pH} 10$. The MCD spectrum contained bands at 14300 and $17000 \mathrm{~cm}^{-1}$ and shoulders at $18000,14300,25700$, and $28400 \mathrm{~cm}^{-1}$, all of which showed little/no field or temperature dependence across the full temperature $(5-55 \mathrm{~K})$ and full magnetic field ranges $(3-7 \mathrm{~T}$ ) employed in the study (Figures 5 and S9). Thus, all of the bands in the MCD spectra $(<55 \mathrm{~K})$ arise from straightforward CD transitions. This observation establishes a singlet $S=0$ ground state for the purple species $\leq 55 \mathrm{~K}$, where the small variation recorded ( $<15 \%$ of band intensity) can be assigned to the $15-20 \%$ fraction of $\mathrm{Cu}$ (II) - LsAA9 resting state that remained in the sample (Figure S9), consistent with the EPR studies described above. In regions of the spectrum that did not contain bands from the $C$-term transitions of $\mathrm{Cu}$ (II)-LsAA9 $\left(21000-23000 \mathrm{~cm}^{-1}\right)$ there was no change in signal intensity over the full temperature range (Figure S9). Therefore, assuming that the lack of temperature variation seen in the MCD spectra requires a Boltzmann distribution of any higher spin state which is less than $2 \%$ (approximate signal-tonoise ratio) of the singlet species, an estimation of an upper limit of the exchange constant between singlet and higher order spin states of $2 J \approx-200 \mathrm{~cm}^{-1}$ may be made (the negative sign indicates antiferromagnetic coupling). In practice, $2 J$ is likely to be much more negative than -200 $\mathrm{cm}^{-1}$ since the low-temperature $(5 \mathrm{~K}) \mathrm{CD}$ spectrum is similar to the room-temperature $\mathrm{CD}$ spectrum, indicating that even at $\sim 300 \mathrm{~K}$ there is no spectroscopically distinct higher spin state. The CD spectrum is not directly sensitive to the magnetic properties of the sample as there is no dependence on the magnetic field, but in switching from a singlet to a triplet electronic configuration, a change in the UV-vis electronic transitions is expected, which would be reflected in the CD spectrum as well.

Resonance Raman Spectroscopy of the Purple Species. Resonance Raman spectroscopy was carried out on the purple species under different isotopic conditions, including preparation of the sample in $\mathrm{H}_{2}{ }^{18} \mathrm{O}$ water, preparation in $\mathrm{H}_{2}{ }^{16} \mathrm{O}$ water with $\mathrm{H}_{2}{ }^{18} \mathrm{O}_{2}$, and preparation in $\mathrm{D}_{2} \mathrm{O}$ water with $\mathrm{H}_{2}{ }^{16} \mathrm{O}_{2}$. 
Under all of these different conditions identical resonance Raman spectra were obtained and no bands were observed to be isotopically sensitive (Figure S10). This overall observation rules out the possibility of the spectroscopic features arising from a $\mathrm{Cu}$-peroxide or $\mathrm{Cu}$-superoxide unit.

The resonance Raman spectra were obtained with 532 and $785 \mathrm{~nm}$ laser excitations, which are associated with the absorptions appearing at 11790,17100 , and $20400 \mathrm{~cm}^{-1}$ in the visible spectrum (Figure S11). With $785 \mathrm{~nm}$ excitation, Raman bands in the spectrum appeared below $700 \mathrm{~cm}^{-1}$ with a prominent band appearing at $352 \mathrm{~cm}^{-1}$ (Figure 6, top). Using
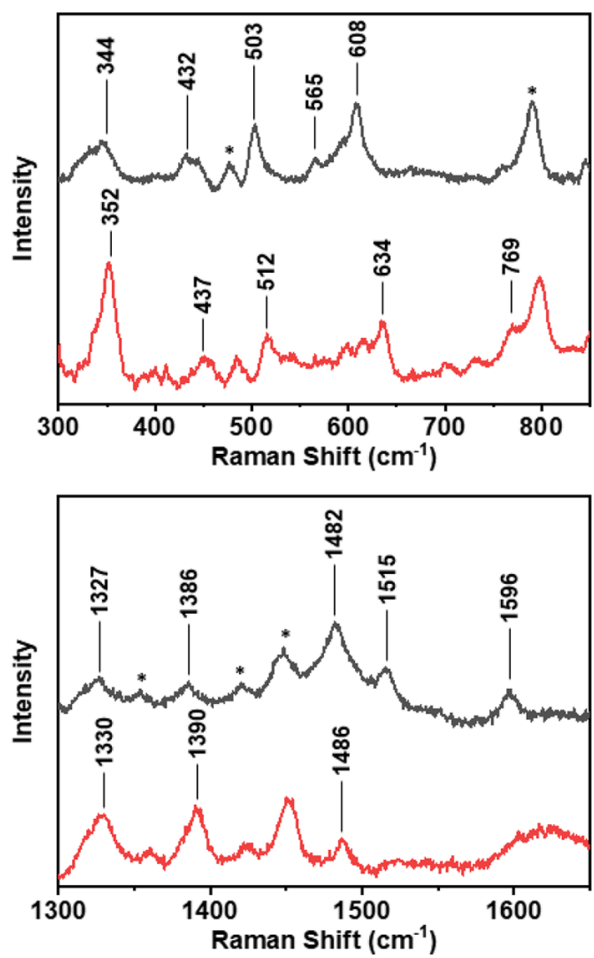

Figure 6. Resonance Raman spectra of the LsAA9 purple species obtained with 532 (black) and $785 \mathrm{~nm}$ (red) excitation, at $293 \mathrm{~K}, 50$ $\mathrm{mM}$ CAPS $\mathrm{pH}$ 10.0. Sample was prepared reacting LsAA9 with $\mathrm{H}_{2}{ }^{16} \mathrm{O}_{2}$ in $\mathrm{H}_{2}{ }^{16} \mathrm{O}$. Asterisk (*) denotes vibrations due to CAPS buffer.

$532 \mathrm{~nm}$ laser excitation, a similar resonance Raman spectrum in the low-energy region was obtained, although the Raman band at $344 \mathrm{~cm}^{-1}$ was comparatively weaker. Conspicuously, excitation at $532 \mathrm{~nm}$ generated a rich Raman spectrum in the high-energy region $\left(1300-1600 \mathrm{~cm}^{-1}\right)$, which is typical for ligand-based vibrational modes. Together, these results are consistent with the electronic transition at $20400 \mathrm{~cm}^{-1}$ being mostly ligand in character, whereas the transition at 11790 $\mathrm{cm}^{-1}$ is significantly metal in character.

A comparison of the resonance Raman spectra of the purple species with those of the oxidized form of galactose oxidase, which contains a $\mathrm{Cu}(\mathrm{II})-$ (modified)tyrosyl radical in the active site (Table 1), shows that bands at 1596, 1482, and 1386 $\mathrm{cm}^{-1}$ have a direct correspondence with bands in the resonance Raman spectra of galactose oxidase. ${ }^{41}$ The similarity in the positions between the two proteins suggests that a $\mathrm{Cu}(\mathrm{II})$-tyrosyl species is also the source of the these bands in the resonance Raman spectrum of the purple species. Bands at $\sim 1330$ and $1515 \mathrm{~cm}^{-1}$ in the spectrum of the purple species are unassigned, but we note that the $7 a^{\prime}(\mathrm{C}-\mathrm{O})$ mode of a noncoordinated tyrosyl is reported at $1516 \mathrm{~cm}^{-1}$. 42 While we
Table 1. Resonance Raman Bands $\left(\mathrm{cm}^{-1}\right)$, above $1300 \mathrm{~cm}^{-1}$, Arising from Irradiation at 532 and $785 \mathrm{~nm}$ of the Purple Species (CAPS buffer, pH 10.0), Together with Comparative Assignments from Raman Bands in Active Galactose Oxidize (G.O.). ${ }^{41}$

\begin{tabular}{cccc}
$532 \mathrm{~nm}$ & $785 \mathrm{~nm}$ & active G.O. & normal mode assignment \\
1596 & & 1595 & $\begin{array}{l}\text { Tyr 8a } \\
\text { free-Tyr } 7 \mathrm{a}^{\prime} ? \\
1515\end{array}$ \\
1482 & 1486 & 1487 & Tyr 7a' \\
1386 & 1390 & 1382 & Tyr 19a \\
1327 & 1330 & & $?$ \\
\hline
\end{tabular}

do not have EPR evidence of a free tyrosyl in the purple species (Figure 4), it is possible that a small amount of photodissociation of the $\mathrm{Cu}-\mathrm{OTyr}$ bond occurs under the laser conditions used in the Raman experiment.

DFT/TD-DFT Analysis of the Purple Species: Predicted Structure, Calculated Vibrational Frequencies, Calculated Exchange Constant, UV-vis, and Pre-Edge XAS Spectral Assignments. The spectroscopic studies are consistent with the presence of a $\mathrm{Cu}(\mathrm{II})$-tyrosyl radical center at the active site of the purple species form of LsAA9. In order to test this hypothesis and to provide a framework within which to interpret the spectroscopic results, we undertook DFT and TD-DFT calculations on models of LsAA9. The models were based on the coordinates of the X-ray crystal structure of LsAA9. We used a cluster model of the active site, which is known from comparison with our previous QM/MM and DFT studies to model faithfully the active site structure of $\mathrm{Cu}$ (II)LsAA9. ${ }^{24 a, c}$

A Cu(II)-tyrosyl electronic state was optimized for both the triplet and the broken symmetry (BS) singlet electronic configurations using the BP86 functional. As the full coordination sphere of the copper in the purple species is unknown, we explored several different models that differed in the type of exogenous ligands $\left(\mathrm{H}_{2} \mathrm{O} / \mathrm{HO}^{-}\right)$which coordinate to the copper and their cis or trans position with respect to the tyrosyl radical (Figure S12). The optimization on the BS singlet surface of these models showed differences with respect to those calculated on the triplet surfaces, most notably for Model3- $\mathrm{OH}_{\text {trans }}$ (Table S1), where the principal difference between the two structures was the length of the $\mathrm{Cu} \cdots \mathrm{OTyr}$ contact (ca. 2.0 $\AA$ in the singlet-optimized structure and ca. 2.4 $\AA$ in the triplet-optimized structure). Therefore, given the large differences in structures between singlet and triplet states, the exchange coupling constants were calculated for both the broken-symmetry (BS) singlet and the triplet-optimized geometries. In all cases, as expected, a single-point BS calculation using B3LYP as functional from the triplet optimized geometry gave the lowest energy state with a positive $J$ value (i.e., ferromagnetic coupling). In contrast, performing the single-point calculation with the singletoptimized geometry resulted in two structures with a modest (Model2- $\mathrm{H}_{2} \mathrm{O}_{\text {trans }}, J=-132 \mathrm{~cm}^{-1}$ ) and strong (Model3$\mathrm{OH}_{\text {trans }}, J=-1004 \mathrm{~cm}^{-1}$ ) antiferromagnetic coupling (Table S2, Figure 7). Both of these structures had a short $\mathrm{Cu}-\mathrm{OTyr}$ bond, 2.19 and $2.01 \AA$, respectively, albeit slightly longer than the equivalent bond observed in $\mathrm{Cu}(\mathrm{II})$-phenoxyl radical complexes $(1.94 \AA))^{43}$

Mindful of the well-known issues associated with the accuracy of BS calculations with transition metals and in particular their sensitivity to the degree of Hartree-Fock 


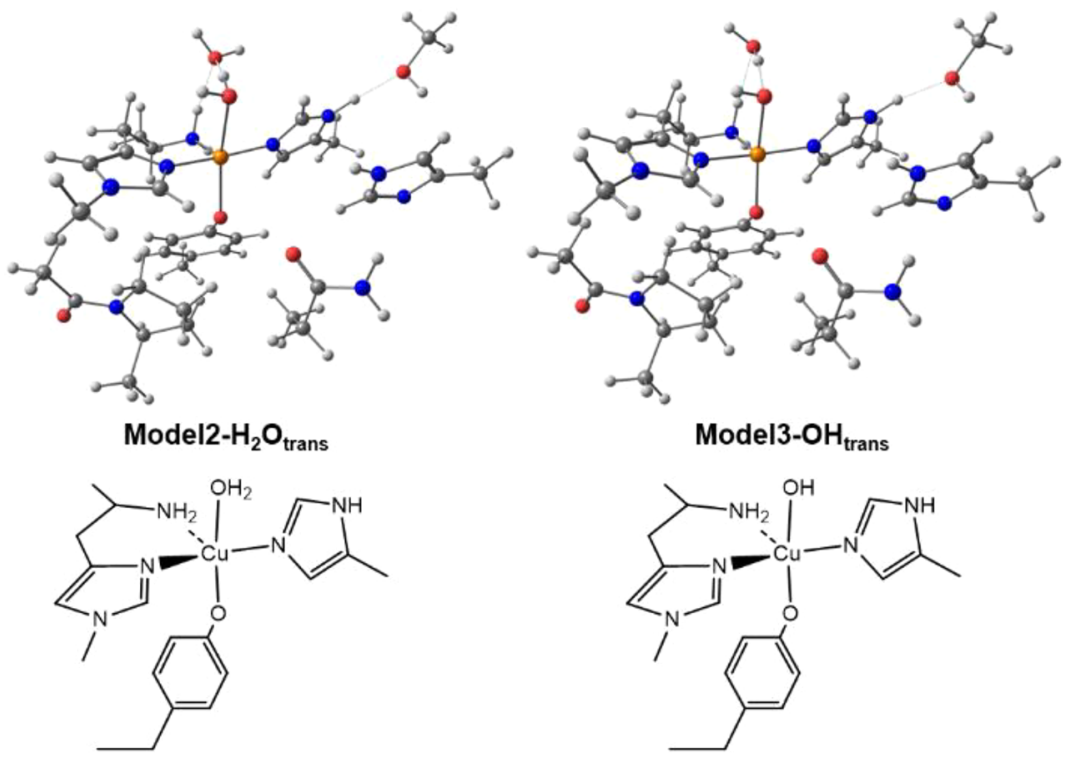

Figure 7. DFT-optimized (broken symmetry singlet state) structures of the LsAA9 cluster Model2- $\mathrm{H}_{2} \mathrm{O}_{\text {trans }}$ and $M o d e l 3-\mathrm{OH}_{\text {trans }}$ together their relative scheme highlighting the $\mathrm{Cu}$ first coordination sphere.

exchange included in the calculations, a range of functionals was then employed to calculate the exchange constant on the BP86-optimized singlet structures (BP86, TPSSh, B3LYP, and PBE0) for all model structures. These functionals were selected to span a range of $0-25 \%$ of Hartree-Fock exchange contribution. Across all of the different functionals, each one predicted a large negative value of exchange constant (much more negative than $-200 \mathrm{~cm}^{-1}$ ) for when the hydroxide lies trans $\left(\right.$ Model3- $-\mathrm{OH}_{\text {trans }}$ ) to the tyrosyl ligand rather than a water molecule in the same position, Model2 $-\mathrm{H}_{2} \mathrm{O}_{\text {trans }}$ (Table S2). The same functionals predicted small exchange constants for the cis configuration, incommensurate with experimental measurements. Thus, all functionals predict a large singlettriplet energy gap for the trans hydroxide configuration.

Time-dependent DFT calculations of the UV-vis spectra and $\mathrm{Cu}$ K-edge XAS were performed on Model2- $\mathrm{H}_{2} \mathrm{O}_{\text {trans }}$ and Model3- $\mathrm{OH}_{\text {trans }}$ in their singlet electronic configuration using the B3LYP functional. For the UV-vis electronic transitions, at least one intense band was predicted in the visible region for both models, together with lower intensity bands (Figure S13). In Model2- $\mathrm{H}_{2} \mathrm{O}_{\text {trans }}$ the most intense band was calculated to appear at $24800 \mathrm{~cm}^{-1}$ and arose from a MLCT transition $(\mathrm{Cu}$ to Tyr-radical) according to its transition difference density (Figure S14). A second, less intense, transition at $15500 \mathrm{~cm}^{-1}$ came from a LMCT (Tyr-radical to $\mathrm{Cu}$ ) transition. For Model3- $\mathrm{OH}_{\text {trans }}$ an intense MLCT (and with significant $\mathrm{HO}^{-}$ character) was predicted at $12390 \mathrm{~cm}^{-1}$, together with a set of LLCT (histidine to tyrosine) and LMCT (histidine to $\mathrm{Cu}$ ) transitions at higher energy (21 800 and $\left.25500 \mathrm{~cm}^{-1}\right)$. These results assigned opposite character to the low-energy transition $\left(\sim 11800 \mathrm{~cm}^{-1}\right)$ in the UV-vis spectrum of the purple species, LMCT for Model2- $\mathrm{H}_{2} \mathrm{O}_{\text {trans }}$, and MLCT for Model3-OH $-\mathrm{O}_{\text {trans }}$. Similarly, the nature of the higher energy transition (20 400 $\mathrm{cm}^{-1}$ ) between the two models was predicted to be different in nature: MLCT for Model2- $\mathrm{H}_{2} \mathrm{O}_{\text {trans }}$, His to Tyr (LLCT) and His to $\mathrm{Cu}$ (LMCT) for Model3- $\mathrm{OH}_{\text {trans }}$. These results are in partial agreement with the experimental spectrum as the relative intensities of the experimental transitions are not modeled accurately. The discrepancy between experimental and calculated intensities likely arises from significant multi- configurational character of the copper(II)-tyrosyl species. In this case, multireference calculations would be needed to model the UV-vis spectrum; these calculations will be considered in a future study.

The TD-DFT-calculated K-pre-edge XAS of both Model2$\mathrm{H}_{2} \mathrm{O}_{\text {trans }}$ and Model3- $\mathrm{OH}_{\text {trans }}$ exhibit two weak features, the first at $\sim 8977 \mathrm{eV}$ (for both models) and another at higher energy 8981.5 and $8980.0 \mathrm{eV}$, respectively (Figure S15). The first feature is assigned to a standard $\mathrm{Cu} 1 \mathrm{~s} \rightarrow 3 \mathrm{~d}$ transition $(8977 \mathrm{eV})$, while the second corresponds to a MLCT from $\mathrm{Cu}$ $1 \mathrm{~s}$ to the tyrosyl radical. The calculated energy separation (4.3 and $2.3 \mathrm{eV}$, respectively) between the two features is smaller than that determined experimentally $(5.0 \mathrm{eV})$; however, the exact energy of the calculated transitions is known to be heavily dependent on the functional chosen for the calculation and is therefore not generally predictive. On the other hand, the number and intensities of the calculated peaks are more reliably predicted from calculations, and from this perspective, the match between experiment and theory is excellent. ${ }^{44}$

Vibrational frequencies were calculated at the same level of theory used for geometry optimization (BP86, Def2-TZVP/ Def2-SVP, see DFT methods section) and gave Raman active vibrations for both Model3- $\mathrm{OH}_{\text {trans }}$ and Model2- $\mathrm{H}_{2} \mathrm{O}_{\text {trans }}$ at similar frequencies to those observed experimentally (Table S5). The C-O tyrosyl stretch (Tyr $7 \mathrm{a}^{\prime}$ ) is calculated at 1455 and $1451 \mathrm{~cm}^{-1}$, respectively (cf. $\sim 1482-1486 \mathrm{~cm}^{-1}$ ), and a $\mathrm{Cu}-\mathrm{OTyr}$ stretch at 375 and $320 \mathrm{~cm}^{-1}$, respectively (cf. 344$352 \mathrm{~cm}^{-1}$ ). On the basis of the calculated $J$ value, TD-DFT, and vibrational calculations, the most plausible structure for the purple species possesses a hydroxide ligand that lies trans to the tyrosyl ligand (Model3- $\mathrm{OH}_{\text {trans }}$ in Figure 7 ), although we cannot rule out the model where a water molecule lies trans to the tyrosyl, Model2 $-\mathrm{H}_{2} \mathrm{O}_{\text {trans }}$.

From the DFT and TD-DFT studies it is not possible to make a definitive conclusion on which model (Model2$\mathrm{H}_{2} \mathrm{O}_{\text {trans }}$ or Model3-OH $\mathrm{OH}_{\text {trans }}$ ) best represents the structure of the purple species. Both are consistent with the experimental and calculated data. However, the lack of $\mathrm{pH}$ sensitivity of the purple species might argue more for Model3- $\mathrm{OH}_{\text {trans }}$ being the representative species. 


\section{DISCUSSION}

Assignment of Spectroscopic Features. The addition of hydrogen peroxide to a $\sim 1 \mathrm{mM}$ solution of LsAA9 LPMO (in either the $\mathrm{Cu}(\mathrm{II})$ or $\mathrm{Cu}(\mathrm{I})$ form) at $\mathrm{pHs}>7.0$ affords a purplecolored species. The dependence of the absorptions within the visible spectrum on the presence of copper shows that they arise from transitions associated with the copper active site. The combined XAS, EPR, and MCD spectroscopic data establish the species as an open-shell singlet in which one unpaired electron is associated with the $\mathrm{Cu}$ (II) center (from XAS) and the other with a coordinating ligand. This ligand cannot be a peroxide or a coordinated water molecule, since the resonance Raman spectra are insensitive to the isotopic substitution of peroxide. The observation also rules out the formation of an antiferromagnetically coupled $\mathrm{Cu}_{2}-\mu$-peroxo dimer. Of the remaining ligands that could harbor an unpaired electron, the active site tyrosine offers the most reasonable possibility, and indeed, resonance Raman data of the purple species are best assigned by comparison to the oxidized form of galactose oxidase, which is known to contain a $\mathrm{Cu}(\mathrm{II})-$ (modified)tyrosyl radical pair. ${ }^{34}$ We further considered the potential formation of an $\mathrm{N}$-oxide at the amino terminus, but this species would be expected to have a prominent $\mathrm{N}-\mathrm{O}$ vibration in the resonance Raman spectrum at $800 \mathrm{~cm}^{-1}$, which is not observed. Also, while the spectroscopic data do not completely rule out a potential $\mathrm{Cu}(\mathrm{II})$-semiquinone species which could arise from the covalent oxidative modification of the tyrosine, the possibility is very much reduced by the lack of any observable modification of the tyrosine in the mass spectrum of the purple species and by the absence of isotopic shifts in the resonance Raman spectra. ${ }^{45}$

To secure the assignment of the purple species as a $\mathrm{Cu}(\mathrm{II})-$ tyrosyl center, we note the appearance of a weak pre-edge feature in the XAS $(8982 \mathrm{eV})$ which is not present in the $\mathrm{Cu}(\mathrm{II})-L s \mathrm{AA} 9$ spectrum. On the basis of previous examples of similar features in the XAS spectra of $\mathrm{Cu}(\mathrm{II})$ complexes and the TD-DFT calculations, this pre-edge feature is assigned to a 1s to SOMO transition where the SOMO has significant tyrosyl character. ${ }^{39,40}$ The fact that this XAS transition has some intensity, along with the observed CT transition at 11790 $\mathrm{cm}^{-1}$ in the visible spectrum of the purple species, demonstrates that there is an appreciable overlap between the SOMOs of the tyrosyl and the $\mathrm{Cu}$ center. While unusual, the occurrence of second pre-edge peaks in the XAS spectra of metal complexes is not unprecedented, having been observed in complexes where strongly coordinated ligands which have low-lying empty $\pi^{*}$ orbitals gain $\sigma$-overlap with the $\mathrm{Cu}$ orbitals through distortion of the ligand. ${ }^{39,40,45}$ Such an interaction could arise in LsAA9 where structures show that the conformation of the tyrosine with respect to the $\mathrm{Cu}$ admits some overlap of the $\pi$-manifold orbitals of the tyrosyl with the $\mathrm{Cu} 3 \mathrm{~d}\left(x^{2}-y^{2}\right)$ orbital (Figure 8). Notably, this orbital pathway can only exist if the $3 \mathrm{~d}\left(x^{2}-y^{2}\right)$ orbital plane of the $\mathrm{Cu}$ is rotated out of the plane of the histidine brace toward the tyrosine $\mathrm{O}$ atom. This rotation further requires the presence of an exogenous ligand in the trans position to the tyrosyl (Figure 8), matching the best-fit models from DFT calculations. Previous structural studies have shown this exogenous ligand is displaced on the binding of substrate, thus linking the formation of the purple species with the absence of substrate, as also observed experimentally herein.
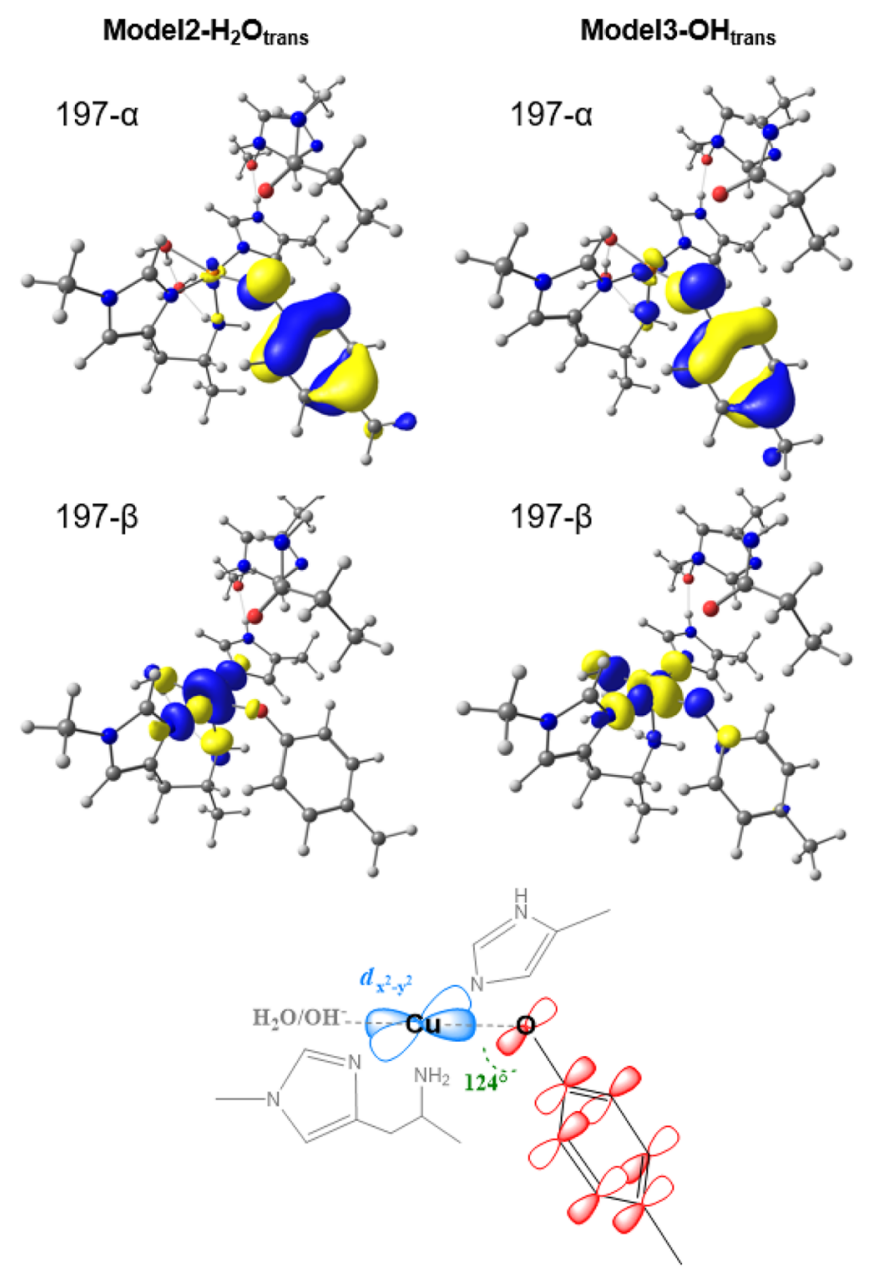

Figure 8. DFT-calculated unrestricted corresponding orbitals representing the two magnetically coupled SOMO in the singlet state of Model2- $\mathrm{H}_{2} \mathrm{O}_{\text {trans }}$ and Model3- $\mathrm{OH}_{\text {trans }}$ together with a scheme showing the rotation of the $\mathrm{d}\left(x^{2}-y^{2}\right)$ orbital with respect to the histidine brace plane. In the X-ray crystal structure of LsAA9 (PDB 5ACG) the $\mathrm{Cu}-\mathrm{O}-\mathrm{C}$ angle is $124^{\circ}$, while the dihedral angle between the $\mathrm{d}\left(x^{2}-y^{2}\right)$ plane and the plane of the phenyl ring of the coordinated tyrosine is $87^{\circ}$.

Further evidence that the purple species is a $\mathrm{Cu}(\mathrm{II})$-tyrosyl pair is gained from comparison with known small-molecule complexes, where experimental determination of the value of the exchange constant $J$ as a function of the $\mathrm{Cu}-\mathrm{O}-\mathrm{C}$ angle (Figure 8) shows that a singlet ground state is only observed when this angle is near $130^{\circ}$ (and the $\mathrm{Cu}-\mathrm{O}-\mathrm{C}-\mathrm{C}$ dihedral angle $\left.\approx 90^{\circ}\right) .{ }^{46}$ In $L s A A 9$ the equivalent angles are $124^{\circ}$ and $87^{\circ}$, respectively. Finally, we note here that careful inspection of the K-edge XAS spectrum of oxidized $\mathrm{Cu}$ (II) in galactose oxidase shows a similar pre-edge feature at $\sim 8985 \mathrm{eV}$, which was assigned at the time to small differences in coordination geometry between the oxidized and the reduced versions of the enzyme but now we would suggest represents the transition described above. ${ }^{47}$

Thus, the data presented herein are commensurate with the formation of an intensely colored, stable $\mathrm{Cu}(\mathrm{II})-$ tyrosyl complex, which is formed during the noncoupled turnover of an AA9 LPMO with hydrogen peroxide. This species has an open-shell singlet ground state, in accord with the formation of a strong $\mathrm{Cu}(\mathrm{II})-\mathrm{O}$ bond, leading to intense charge-transfer bands in its visible spectrum. 


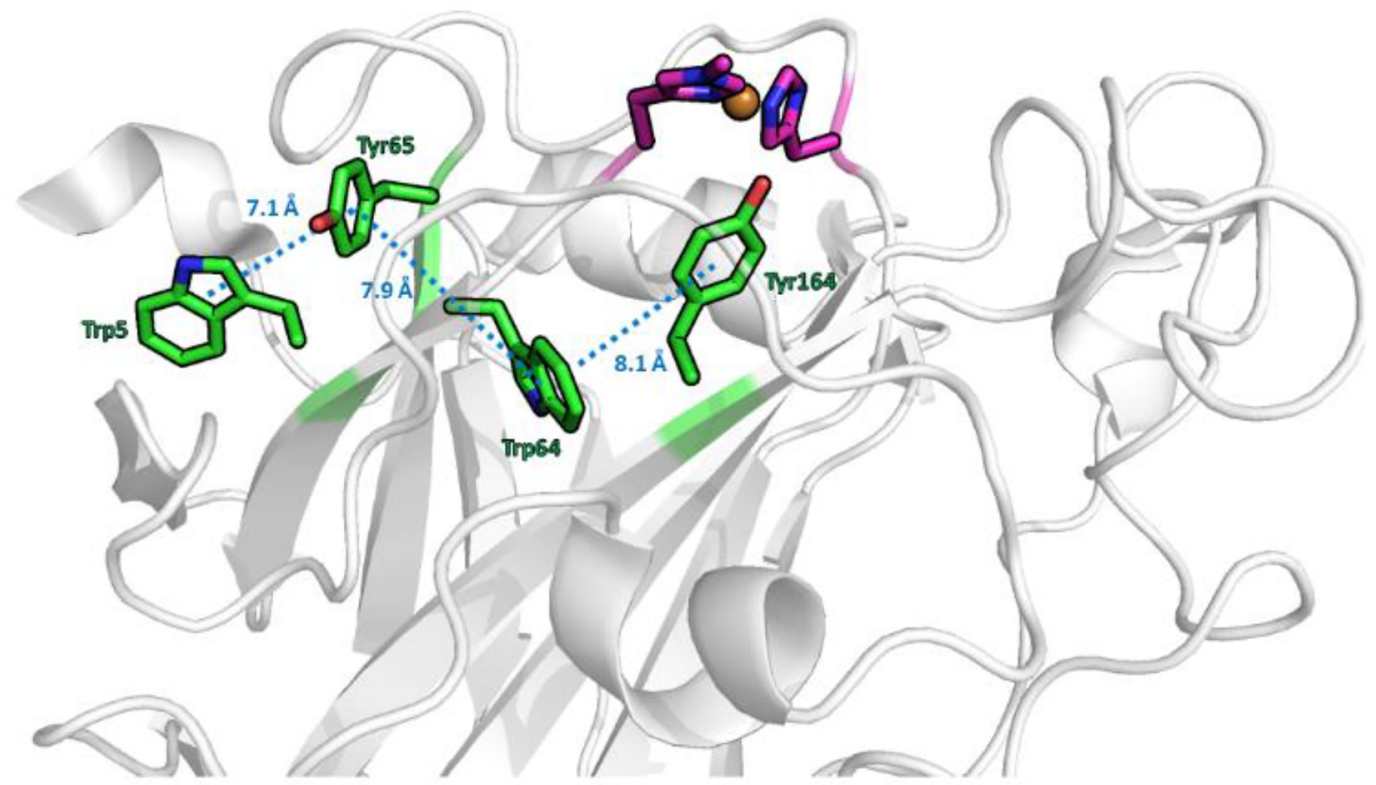

Figure 9. Depiction of LsAA9 structure (gray ribbons) and amino acid side chains (cylinder bonds in green) involved in putative hole-hopping pathway. $\mathrm{Cu}$ ion is represented as an orange sphere, and distances are given in Angstroms.

Hydrogen Peroxide as a Cosubstrate for LPMOs. Formation of the tyrosyl radical at the active site of LsAA9 provides evidence that this is the site of generation of the oxidizing species in LPMOs, following addition of hydrogen peroxide. Hydrogen peroxide is a powerful oxidant, and its use as a cosubstrate in the reactions of LPMOs has been the center of much recent debate. ${ }^{4 c, 48}$ This debate concerns itself with whether hydrogen peroxide or $\mathrm{O}_{2} /$ reducing agent are the in vivo cosubstrates for LPMOs. While acknowledging that the peroxide $/ \mathrm{O}_{2}$ debate is not settled, our own working hypothesis for the work described herein is that hydrogen peroxide is a useful laboratory shunt for AA9 LPMOs for both coupled and uncoupled activities. In the former role it acts to simplify mechanistic studies, while in the latter it gives insight into the structural apparatus which LPMOs employ to deal with oxidizing intermediates generated at the active site in the absence of substrate. From this perspective we have shown herein that AA9 LPMOs are significantly protected from oxidative damage by their own glycosylation patterns. We also observe that some amino acid side chains (both at the surface and buried within the protein structure) are covalently modified after treatment with hydrogen peroxide (Figure 3), suggesting that these amino acids are redox active. This last aspect directs us toward the possibility that LPMOs are equipped with specific internal charge-transfer mechanisms for dealing with the oxidizing species which are generated during its catalytic cycle-a proposal already made by others, ${ }^{22 a}$ particularly given the parallels to $\mathrm{P} 450$ and also to the fact that the active site in LPMOs is surrounded by amino acid residues (e.g., tryptophans and tyrosines) that are in principle capable of translating a positive hole away from the active site. ${ }^{49}$

Role for the Active Site Tyrosine in LPMOs. Mass spectrometry analysis shows that challenging LsAA9 with hydrogen peroxide during uncoupled turnover does not lead to covalent oxidative modification of the active site tyrosine (Tyr164). Not only does this observation take this LPMO away from the class of other copper-containing enzymes that possess tyrosine-derived redox-active cofactors (e.g., quinones), it also provides evidence that the tyrosyl is converted to a tyrosine by an efficient charge-transfer mechanism within the protein. Inspection of the LsAA9 structure shows that such mechanism could exist whereby the tyrosyl radical at the active site is quickly reduced to a tyrosine by a combination of rapid hole hopping from Trp-64 (8.1 Å away, Figure 9) and back proton transfer from water. The tryptophan cation is subsequently reduced by other amino acid side chains along a chargetransfer pathway (see below).

Taking the above discussion as a basis for the role of the tyrosine in the active site of LPMOs, any potential holehopping pathways and the rates at which charge transfer occurs through these pathways can be examined using Marcus theory. The rate constant for any donor-acceptor pairwise interaction along a hole-hopping pathway can be estimated using a chargetransfer rate expression as follows ${ }^{50}$

$$
k_{\mathrm{DA}}=\frac{2 \pi}{\hbar} V_{\mathrm{DA}}^{2} \frac{1}{\sqrt{4 \pi \lambda_{\mathrm{DA}} T}} \exp \left(-\frac{\left(\Delta G^{\circ}+\lambda_{\mathrm{DA}}\right)^{2}}{4 \lambda_{\mathrm{DA}} k_{\mathrm{B}} T}\right)
$$

Elements of the equation can be calculated/estimated from the known self-exchange reorganization energies of the donor $\left(\lambda_{\mathrm{DD}}\right)$ and acceptor $\left(\lambda_{\mathrm{AA}}\right)$, the reduction potentials of the donor and acceptor, and the distances between the donor and the acceptor, the last of which is obtained from structural information. The effective electronic coupling $\left(V_{\mathrm{DA}}\right)$ can be estimated using Hopfield's equation. ${ }^{51}$ On the basis of the charge-transfer rate expression, a protein structure can then be searched for potential hole-hopping pathways and their rates calculated. To this end, a computer program, EHPath, is available to perform this search rapidly. ${ }^{52}$

Accordingly, we applied EHPath to all of the potential holehopping residues (tyrosine, tryptophan, cysteine) within the known structure of $L s A A 9^{2}$ using reduction potentials and reorganization energies at $\mathrm{pH} 7$ and where the tyrosine at the active site (Tyr-164) acts as the hole donor. From this analysis a single and clear hole-hopping pathway in LsAA9 emerges, which transfers a hole away from the tyrosyl radical (Tyr-164) to a surface residue (Trp-5) through Trp-64 and Tyr-65 with a 
mean-residence time of $6 \mathrm{~ms}$ (Figure 9). All other pathways in the protein have residence times of $>1 \mathrm{~s}$ (Table 2$)$. The rapid

Table 2. Five Fastest Accurate Mean-Residence Times (AMRT) of Hole-Hopping Pathways from Tyr-164 at pH 7 and 298.15 K through the Structure of LsAA9, As Determined by EHPath ${ }^{52}$

\begin{tabular}{cl}
\multicolumn{1}{c}{ pathway } & \multicolumn{1}{c}{ AMRT/s } \\
\hline Tyr-164, Trp-64, Tyr-65 & $6.0 \times 10^{-3}$ \\
Tyr-164, Trp-64, Tyr-65, Trp-5 & $6.3 \times 10^{-3}$ \\
Tyr-164, Tyr-65, Trp-5 & 1.2 \\
Tyr-164, Trp-64, Trp-5 & 1.5 \\
Tyr-164, Trp-64, Tyr-65, Tyr-21, Trp-5 & 1.8 \\
\hline
\end{tabular}

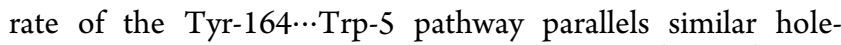
hopping pathways seen in the enzymes P450 (37 ms), BSS $(4.5 \mathrm{~ms})$, and CCP1 $(2.5 \mathrm{~ms}) .^{52} \mathrm{In}$ a further parallel to these enzymes, the calculated activation energy of $\mathrm{H}$-atom abstraction from substrate in coupled turnover by LsAA9 is low $\left(\Delta G^{\ddagger}=5.5 \mathrm{kcal} \mathrm{mol}^{-1}\right.$ from QM/MM calculations) such that the rate of $\mathrm{H}$-atom abstraction can be expected to be faster than the rate of hole hopping. As such, it is evident that the active-site tyrosine in LsAA9 along with adjacent Trp-64 could form part of an efficient charge-transfer pathway through LPMOs at $\mathrm{pH} 7$, which is active during uncoupled turnover of the LPMO. It should be noted here that the network of aromatic residues connecting the $\mathrm{Cu}$ active site to the outside of the protein is largely conserved in the AA9 family. ${ }^{20}$

The formation of the $\mathrm{Cu}(\mathrm{II})$-tyrosyl species at $\mathrm{pHs}>7$ observed in our experiments is likely to be due to a combination of three factors. The first is, straightforwardly, that the active site tyrosine is easier to oxidize at higher $\mathrm{pHs}$ (reduction potential of tyrosyl is $\sim 0.7 \mathrm{~V}$ at $\mathrm{pH} 10$ and $0.93 \mathrm{~V}$ at $\mathrm{pH} 7) .{ }^{53}$ The second is that our MS results show that several redox-active residues, including those in the hole-hopping pathway, are covalently modified in the experiment, thereby compromising the protein's capacity to transfer charge away from the active site tyrosine. In such circumstances it may be that there is an effective buildup of tyrosyl radical at the active site, which-under the conditions employed in our study-is eventually "extinguished" by the formation of a stable $\mathrm{Cu}(\mathrm{II})-$ tyrosyl bond (i.e., purple species). Third, the formation of the bond occurs through a process which involves a $\mathrm{pH}$-dependent reorganization of the $\mathrm{Cu}$ coordination sphere as described above.

Roles of Substrate in the Turnover of LPMOs. The $\mathrm{Cu}(\mathrm{II})$-tyrosyl radical species does not form in the presence of substrate. This finding highlights two factors in AA9 LPMO (bio)chemistry. The first is that the presence of a bound substrate changes the mechanistic pathways available to AA9 LPMOs, ostensibly by locking the copper equatorial coordination sites into the plane of the histidine brace ligands. The locking is achieved by displacement of the axial water molecule in the $\mathrm{Cu}$ coordination sphere and increasing the $\sigma$ donation capacity of the $\mathrm{NH}_{2}$ ligand, as previously demonstrated by EPR studies on LsAA9. ${ }^{2}$

Second, the presence of an efficient hole-hopping pathway in LPMOs confounds kinetic comparisons between the relative reactivity of $\mathrm{H}_{2} \mathrm{O}_{2}$ and $\mathrm{O}_{2} /$ reducing agent as cosubstrates. The complication arises since the presence of a soluble reducing agent in the latter allows the hole-hopping mechanism to operate repeatedly to extinguish oxidizing equivalents generated at the active site. This pathway will compete against any weakly coupled pathway with substrate and thereby ostensibly lower the observed rate of reaction of substrate oxidation. Critical aspects in this regard are the availability (concentration) of substrate, its match to the LPMO under study, the presence of a carbohydrate-binding module, and the concentration and oxidation potential of the reducing agent, all of which are factors known to affect the rate of substrate oxidation by LPMOs. ${ }^{25,48,54}$

\section{CONCLUSIONS}

The addition of hydrogen peroxide to an AA9 LPMO at high $\mathrm{pHs}$ in the absence of substrate results in the formation of a highly stable, purple-colored $\mathrm{Cu}(\mathrm{II})$-tyrosyl complex that has been characterized using spectroscopic methods (UV-vis, CD, MCD, resonance Raman, EPR). The copper(II)-tyrosyl bond forms after the slow time scale "rotation" of the copper equatorial plane out of the plane of the histidine brace coordinating atoms. The redox activity of the active site tyrosine is indicative of its role in LPMOs, which is to act as part of an efficient charge-transfer pathway between the active site and the protein surface. Such a pathway, consisting of tyrosine and tryptophan residues and spanning $\sim 15 \AA$, has been identified in the LPMO used in our studies.

\section{METHODS}

Preparation of LsAA9 LPMO. LsAA9 LPMO was purified as reported previously. ${ }^{9,25}$

Formation of the LsAA9 Purple Species. The reduced $\mathrm{Cu}(\mathrm{I})$ state of LsAA9 was generated by reaction of the enzyme with excess ascorbic acid inside a $\mathrm{N}_{2}$ atmosphere glovebox. The excess ascorbic acid was then removed via buffer exchange with a $10 \mathrm{kDa}$ MWCO VivaSpin centrifuge concentrator. All of the solutions used inside the $\mathrm{N}_{2}$ atmosphere glovebox were degassed by freeze-pump-thawing on a Schlenk line (water, buffers) or by purging the solution with $\mathrm{N}_{2}$ for 30 min (protein and $\mathrm{H}_{2} \mathrm{O}_{2}$ solutions). $\mathrm{H}_{2} \mathrm{O}_{2}$ in an appropriate amount was then added to the $\mathrm{Cu}(\mathrm{I})-L s \mathrm{AA} 9$ solution to initiate the reaction. When starting from the $\mathrm{Cu}(\mathrm{II})$ resting state, $\mathrm{H}_{2} \mathrm{O}_{2}$ was simply added to the protein solution without degassing.

LsAA9 Deglycosylation. LsAA9 was incubated with a His-tagged Endoglycosidase $\mathrm{H}$ (Endo $\mathrm{H})$ in a 10:1 molar ratio in $20 \mathrm{mM} \mathrm{Na}-$ phosphate at $\mathrm{pH} 7.2$ for 2 days at room temperature. $\mathrm{NaCl}$ and imidazole were added to the solution up to a final concentration of 500 and $25 \mathrm{mM}$, respectively; then the solution was applied to a $1 \mathrm{~mL}$ HisTrap FF column to remove the Endo $\mathrm{H}$ from the sample. EDTA was added to the flow through to a final concentration of $2 \mathrm{mM}$, and then it was incubated for $2 \mathrm{~h}$ at room temperature. The flow through was then applied to a Superdex $7516 / 600$ column, pre-equilibrated with $20 \mathrm{mM} \mathrm{Na}$-phosphate, $250 \mathrm{mM} \mathrm{NaCl}$ at $\mathrm{pH}$ 7.2. The eluted fractions corresponding to the deglycosylated LsAA9 were then concentrated, copper loaded with 1 equiv of $\mathrm{CuSO}_{4} \cdot 5 \mathrm{H}_{2} \mathrm{O}$, and buffer exchanged in $20 \mathrm{mM} \mathrm{Na}$-phosphate at pH 6.0 with a $3 \mathrm{kDa}$ MWCO VivaSpin centrifuge concentrator.

UV-vis, CD, and MCD Spectroscopies. The UV-vis absorption spectra were acquired on a Shimadzu UV-1800 spectrometer or on a PerkinElmer Lambda 465 diode array spectrophotometer. For the kinetics, the $\mathrm{Cu}(\mathrm{I})-\mathrm{LsAA} 9$ and $\mathrm{H}_{2} \mathrm{O}_{2}$ solutions were prepared as described above. The sample was then transferred to the spectrometer in a sealed cuvette, and an appropriate amount of deoxygenated $\mathrm{H}_{2} \mathrm{O}_{2}$ was quickly added to initiate the reaction.

CD spectra were recorded on a Jasco J810 spectropolarimeter at room temperature. MCD spectra were recorded on a Jasco J-810 spectropolarimeter adapted to incorporate an Oxford Instruments Spectromag SM4000 magnetocryostat. The sample solutions were loaded into cells of ca. $2 \mathrm{~mm}$ path length constructed from quartz discs separated by a rubber ring spacer and frozen in liquid nitrogen. 
The spectra were collected at 3,5 , and $7 \mathrm{~T}$ with temperatures between 5 and $55 \mathrm{~K}$.

EPR Spectroscopy. Continuous-wave X-band frozen solution EPR spectra were acquired on a Bruker micro EMX spectrometer operating at $\sim 9.30 \mathrm{GHz}$ with a modulation amplitude of $4 \mathrm{G}$, modulation frequency of $100 \mathrm{kHz}$, and microwave power of 10.02 $\mathrm{mW}$. The spectra are the summation of 3 scans and were recorded at $170 \mathrm{~K}$. The purple-colored species samples were generated in the same way as for the UV-vis experiments. EPR spin quantitation, via double integration of the spectra, of the paramagnetic $\mathrm{Cu}$ concentration was performed using a $0.200 \mathrm{mM} \mathrm{CuSO}_{4}, 10 \mathrm{mM}$ $\mathrm{HCl}, 2 \mathrm{M} \mathrm{NaClO}_{4}$ standard solution.

The conversion of the $\mathrm{Cu}(\mathrm{II})-L s \mathrm{AA} 9$ resting state to the purple species was estimated via EPR spin quantitation. It was assumed that the $\mathrm{Cu}$ (II) signal reduction was only due to conversion in the purple species. At $\mathrm{pH}$ 10.0, after the reaction with $\mathrm{H}_{2} \mathrm{O}_{2}$, the final $\mathrm{Cu}$ (II) concentration was $75-80 \%$ less than the $\mathrm{Cu}$ (II) resting state at the same protein concentration (i.e., $75-80 \%$ conversion into the purple species). To determine the $\mathrm{Cu}(\mathrm{II})$ concentration of the apoprotein after the purple species reduction and treatment with EDTA, the sample was buffer exchanged, under anaerobic conditions, to remove the excess of reducing agent and the $[\mathrm{Cu}(\mathrm{EDTA})]^{2-}$ complex. The sample was then taken to $\mathrm{pH} 2.0$ by adding $\mathrm{HCl}$ to denature fully the enzyme. The $\mathrm{Cu}(\mathrm{II})$ concentration was then measured by EPR via spin quantitation.

XAS. XAS spectra were collected on a $1.0 \mathrm{mM}$ solution of enzyme LsAA9 at $\mathrm{pH} 10.0$, which had been flash frozen to $77 \mathrm{~K}$. Data were acquired on the sample at $90 \mathrm{~K}$ at the B18 Core Spectroscopy beamline at Diamond Light Source, Oxfordshire, UK. At the time of the measurement the Diamond synchrotron was operating at a ring energy of $3 \mathrm{GeV}$. The beamline was equipped with a $\mathrm{Si}(111)$ doublecrystal monochromator, and harmonic rejection was achieved through the use of two Pt-coated mirrors operating at an incidence angle of 9 mrad. The monochromator was calibrated using the first maximum in the derivative in the edge region of the XAS spectra of a copper foil placed between the second and the third ion chambers at $8979 \mathrm{eV}$. Data were collected in fluorescence mode from 8770 to $9020 \mathrm{eV}$ using a nine-channel $\mathrm{Ge}$ solid-state detector at the copper $\mathrm{K}$ absorption edge $(\sim 8980 \mathrm{eV})$ in $1 \mathrm{eV}$ steps. The measurements were collected at $77 \mathrm{~K}$.

Resonance Raman Spectroscopy. Samples were prepared in the same way as the UV-vis samples but using $\mathrm{H}_{2}{ }^{18} \mathrm{O}_{2}, \mathrm{D}_{2} \mathrm{O}$, or $\mathrm{H}_{2}{ }^{18} \mathrm{O}$ for the isotopically substituted samples. Spectra were collected using a HORIBA XploRA Raman microscope at room temperature using 532 and $785 \mathrm{~nm}$ laser wavelength excitations. The spectrometer gratings used were 2400 and $1200 \mathrm{gr} / \mathrm{mm}$, respectively, together with a confocal pinhole size of $500 \mu \mathrm{m}$ and slit width of $200 \mu \mathrm{m}$. The laser power was $\sim 7 \mathrm{~mW}$. Samples were measured in the liquid state using a $63 \times / 1.0$ dipping objective (Zeiss). To test for heating effects, measurements were also made on the samples in the frozen state facilitated by using a $\mathrm{LN}_{2}$ cooling stage and $100 \times / 0.9$ lens with the rest of the acquisition parameters remaining the same as those used for the liquid sample measurements. The frozen sample results showed no significant spectral differences compared to the liquid state data. Real-time spectral acquisition was also performed to optimize the acquisition parameters (signal-to-noise) and to verify nondestructive testing. To ensure acceptable measurement statistics, $\sim 40$ spectra were collected per sample tested. The spectra were processed (baseline corrected, normalized, averaged) and then analyzed using OriginPro (2018) software with processing and spectral analysis also independently checked using IGOR Pro (v.6.3.7). Accounting for the measurement statistics, the maximum uncertainty associated with the Raman band positions was found to be ca. $\pm 2 \mathrm{~cm}^{-1}$.

Analysis of the Reaction Products. Cellohexaose was used as substrate. One hundred microliter reactions were set up with $750 \mu \mathrm{M}$ cellohexaose, $1 \mathrm{mM}$ ascorbic acid, $100 \mu \mathrm{M} \mathrm{H}_{2} \mathrm{O}_{2}$ (no $\mathrm{H}_{2} \mathrm{O}_{2}$ added in the $\mathrm{O}_{2}$ turnover reactions), and $1 \mu \mathrm{M}$ LsAA9 or purple LsAA9 in 5 $\mathrm{mM} \mathrm{MES}$ at $\mathrm{pH} 7.0$ and were incubated at $40{ }^{\circ} \mathrm{C}$ for $2 \mathrm{~h}$. The reaction was then quenched by addition of 3 reaction volumes of ethanol ( $98 \%$ $\mathrm{v} / \mathrm{v})$. Reactions with $\mathrm{H}_{2} \mathrm{O}_{2}$ were performed inside an $\mathrm{N}_{2}$ atmosphere glovebox. A $1 \mu \mathrm{L}$ amount of sample was then mixed with $2 \mu \mathrm{L}$ of 10 $\mathrm{mg} / \mathrm{mL} 2,5$-dihydroxybenzoic acid in $50 \%$ acetonitrile, $0.1 \%$ trifluoroacetic acid on a Bruker SCOUT-MTP 384 target plate. The spotted samples were then dried in air under a lamp before being analyzed by mass spectrometry on a Ultraflex III matrix-assisted laser desorption ionization-time-of-flight/time-of-flight (MALDI-TOF/TOF) instrument (Bruker), as described previously. ${ }^{9}$ The purple species LsAA9 sample used in the assay was incubated with EDTA overnight to remove $\mathrm{Cu}^{2+}$ from any LsAA9 that had not been converted to the purple species. The resulting $[\mathrm{Cu}(\mathrm{EDTA})]^{2-}$ complex was then removed from the solution by ultracentrifugation through $10 \mathrm{kDa}$ cutoff size-exclusion filters.

DFT. Spin-unrestricted density functional theory (DFT) calculations were performed using the ORCA 4.1 electronic structure package. ${ }^{55}$ The different cluster models were derived from the X-ray crystal structure of LsAA9 (PDB 5ACG). ${ }^{2}$ Geometry optimizations were performed with the $\mathrm{BP} 86^{56}$ functional (with RI approximation), Def2-TZVP basis set ${ }^{57}$ on $\mathrm{Cu}$ and ligating atoms, and Def-2-SVP on all of the remaining atoms; empirical dispersion correction were accounted for using Grimme's D3 method with Becke-Johnson damping (D3BJ); ${ }^{58}$ solvation effects were included with the conductor-like polarizable continuum model (CPCM, $\varepsilon=4.0$ ). The broken symmetry (BS) approach was used to optimize the singlet spin state geometry in each model. Single-point energies were calculated using the B3LYP functional ${ }^{59}$ and the Def2-TZVP basis set on all atoms. Corrected singlet state energies and exchange coupling constants $(J)$ were computed with the Yamaguchi formula ${ }^{60}$

$$
J=\frac{E_{\text {triplet }}-E_{\text {BSsinglet }}}{\left\langle S^{2}\right\rangle_{\text {triplet }}-\left\langle S^{2}\right\rangle_{\text {singlet }}}
$$

$\mathrm{UV}$-vis and $\mathrm{Cu} \mathrm{K}$-edge absorption spectra were calculated with the time-dependent density functional theory (TD-DFT) approach applying the Tamm-Dancoff approximation. ${ }^{61}$ The UV-vis absorption spectra were computed with the B3LYP functional, Def2-TZVP basis set on all atoms, and RIJCOSX ${ }^{62}$ approximation with a dense integration grid (ORCA Grid5). The K-edge calculations were performed on the B3LYP functional together with the ZORA scalar relativistic approximation; ${ }^{63}$ the $\mathrm{CP}(\mathrm{PPP})$ basis set ${ }^{64}$ was used on the $\mathrm{Cu}$ and the ZORA-Def2-TZVP basis set ${ }^{65}$ on all other atoms. In the TD-DFT approach, the description of the core hole leads to a systematic error in the absolute energy transitions, which can be compensated by a constant energy shift (which is characteristic for each functional and basis set). ${ }^{66}$ Here, the calculated $1 \mathrm{~s} \rightarrow 3 \mathrm{~d}$ preedge transition of the $\mathrm{Cu}(\mathrm{II})$ resting state model was used to calibrate the method. An energy shift of $-5.8 \mathrm{eV}$ was applied to all calculated transitions. Full details on the cluster models and the coordinates of the optimized geometries can be found in the Supporting Information.

LC-MS/MS. Full details on the experimental procedure and data analysis for LC-MS/MS can be found in the Supporting Information.

\section{ASSOCIATED CONTENT}

\section{S Supporting Information}

The Supporting Information is available free of charge on the ACS Publications website at DOI: 10.1021/jacs.9b09833.

Experimental procedures, spectroscopic information, mass spectral information, TD-DFT results, and coordinates of DFT-optimized structures (PDF)

\section{AUTHOR INFORMATION}

\section{Corresponding Authors}

*gideon.davies@york.ac.uk

*paul.walton@york.ac.uk

ORCID

Alessandro Paradisi: 0000-0001-8775-9367 
Esther M. Johnston: 0000-0001-7807-4729

Morten Tovborg: 0000-0001-9612-5315

Callum R. Nicoll: 0000-0002-2122-9387

Luisa Ciano: 0000-0002-1667-0856

Adam Dowle: 0000-0002-6501-5444

Jonathan McMaster: 0000-0003-0917-7454

Y. Hancock: 0000-0003-4799-2783

Gideon J. Davies: 0000-0002-7343-776X

Paul H. Walton: 0000-0002-1152-1480

\section{Author Contributions}

${ }^{\ddagger}$ A.P. and E.M.J.: These authors contributed equally.

\section{Notes}

The authors declare the following competing financial interest(s): Novozymes is a commercial enzyme producer.

\section{ACKNOWLEDGMENTS}

We thank Dr. Giannantonio Cibin and Diamond Light Source for experimental support. We acknowledge the Biotechnology and Biological Sciences Research Council for support under grant no. BB/R007705. G.J.D. acknowledges the Royal Society for the provision of a Murray Research Professorship. Y.H. acknowledges the University of York Strategic Capital Equipment award for the Raman spectrometer and associated equipment accessories. A.P. and P.H.W. thank Mrs. Lesley Wild for support.

\section{REFERENCES}

(1) (a) Quinlan, R. J.; Sweeney, M. D.; Lo Leggio, L.; Otten, H.; Poulsen, J.-C. N.; Johansen, K. S.; Krogh, K. B. R. M.; Jørgensen, C. I.; Tovborg, M.; Anthonsen, A.; Tryfona, T.; Walter, C. P.; Dupree, P.; Xu, F.; Davies, G. J.; Walton, P. H. Insights into the oxidative degradation of cellulose by a copper metalloenzyme that exploits biomass components. Proc. Natl. Acad. Sci. U. S. A. 2011, 108 (37), 15079-15084. (b) Vaaje-Kolstad, G.; Westereng, B.; Horn, S. J.; Liu, Z.; Zhai, H.; Sørlie, M.; Eijsink, V. G. H. An oxidative enzyme boosting the enzymatic conversion of recalcitrant polysaccharides. Science 2010, 330 (6001), 219-222. (c) Bissaro, B.; Røhr, Å. K.; Müller, G.; Chylenski, P.; Skaugen, M.; Forsberg, Z.; Horn, S. J.; Vaaje-Kolstad, G.; Eijsink, V. G. H. Oxidative cleavage of polysaccharides by monocopper enzymes depends on $\mathrm{H}_{2} \mathrm{O}_{2}$. Nat. Chem. Biol. 2017, 13, 1123. (d) Phillips, C. M.; Beeson, W. T.; Cate, J. H.; Marletta, M. A. Cellobiose Dehydrogenase and a CopperDependent Polysaccharide Monooxygenase Potentiate Cellulose Degradation by Neurospora crassa. ACS Chem. Biol. 2011, 6 (12), 1399-1406. (e) Meier, K. K.; Jones, S. M.; Kaper, T.; Hansson, H.; Koetsier, M. J.; Karkehabadi, S.; Solomon, E. I.; Sandgren, M.; Kelemen, B. Oxygen Activation by $\mathrm{Cu}$ LPMOs in Recalcitrant Carbohydrate Polysaccharide Conversion to Monomer Sugars. Chem. Rev. 2018, 118 (5), 2593-2635.

(2) Frandsen, K. E. H.; Simmons, T. J.; Dupree, P.; Poulsen, J.-C. N.; Hemsworth, G. R.; Ciano, L.; Johnston, E. M.; Tovborg, M.; Johansen, K. S.; von Freiesleben, P.; Marmuse, L.; Fort, S.; Cottaz, S.; Driguez, H.; Henrissat, B.; Lenfant, N.; Tuna, F.; Baldansuren, A.; Davies, G. J.; Lo Leggio, L.; Walton, P. H. The molecular basis of polysaccharide cleavage by lytic polysaccharide monooxygenases. Nat. Chem. Biol. 2016, 12, 298.

(3) Ciano, L.; Davies, G. J.; Tolman, W. B.; Walton, P. H. Bracing copper for the catalytic oxidation of $\mathrm{C}-\mathrm{H}$ bonds. Nat. Catal. 2018, 1 (8), 571-577.

(4) (a) Hemsworth, G. R.; Johnston, E. M.; Davies, G. J.; Walton, P. H. Lytic Polysaccharide Monooxygenases in Biomass Conversion. Trends Biotechnol. 2015, 33 (12), 747-761. (b) Horn, S. J.; VaajeKolstad, G.; Westereng, B.; Eijsink, V. G. H. Novel enzymes for the degradation of cellulose. Biotechnol. Biofuels 2012, 5 (1), 45. (c) Chylenski, P.; Bissaro, B.; Sørlie, M.; Røhr, Å. K.; Várnai, A.;
Horn, S. J.; Eijsink, V. G. H. Lytic Polysaccharide Monooxygenases in Enzymatic Processing of Lignocellulosic Biomass. ACS Catal. 2019, 9 (6), 4970-4991.

(5) Loose, J. S. M.; Forsberg, Z.; Fraaije, M. W.; Eijsink, V. G. H.; Vaaje-Kolstad, G. A rapid quantitative activity assay shows that the Vibrio cholerae colonization factor GbpA is an active lytic polysaccharide monooxygenase. FEBS Lett. 2014, 588 (18), 34353440 .

(6) Walton, P. H.; Davies, G. J. On the catalytic mechanisms of lytic polysaccharide monooxygenases. Curr. Opin. Chem. Biol. 2016, 31, 195-207.

(7) Gao, J.; Thomas, D. A.; Sohn, C. H.; Beauchamp, J. L. Biomimetic Reagents for the Selective Free Radical and Acid-Base Chemistry of Glycans: Application to Glycan Structure Determination by Mass Spectrometry. J. Am. Chem. Soc. 2013, 135 (29), 1068410692.

(8) Span, E. A.; Suess, D. L. M.; Deller, M. C.; Britt, R. D.; Marletta, M. A. The Role of the Secondary Coordination Sphere in a Fungal Polysaccharide Monooxygenase. ACS Chem. Biol. 2017, 12 (4), $1095-1103$.

(9) Hemsworth, G. R.; Henrissat, B.; Davies, G. J.; Walton, P. H. Discovery and characterization of a new family of lytic polysaccharide mono-oxygenases. Nat. Chem. Biol. 2014, 10, 122-126.

(10) (a) Lo Leggio, L.; Simmons, T. J.; Poulsen, J. C.; Frandsen, K. E.; Hemsworth, G. R.; Stringer, M. A.; von Freiesleben, P.; Tovborg, M.; Johansen, K. S.; De Maria, L.; Harris, P. V.; Soong, C. L.; Dupree, P.; Tryfona, T.; Lenfant, N.; Henrissat, B.; Davies, G. J.; Walton, P. H. Structure and boosting activity of a starch-degrading lytic polysaccharide monooxygenase. Nat. Commun. 2015, 6, 5961. (b) Vu, V. V.; Beeson, W. T.; Span, E. A.; Farquhar, E. R.; Marletta, M. A. A family of starch-active polysaccharide monooxygenases. Proc. Natl. Acad. Sci. U. S. A. 2014, 111 (38), 13822-13827.

(11) Couturier, M.; Ladevèze, S.; Sulzenbacher, G.; Ciano, L.; Fanuel, M.; Moreau, C.; Villares, A.; Cathala, B.; Chaspoul, F.; Frandsen, K. E.; Labourel, A.; Herpoël-Gimbert, I.; Grisel, S.; Haon, M.; Lenfant, N.; Rogniaux, H.; Ropartz, D.; Davies, G. J.; Rosso, M.N.; Walton, P. H.; Henrissat, B.; Berrin, J.-G. Lytic xylan oxidases from wood-decay fungi unlock biomass degradation. Nat. Chem. Biol. 2018, 14, 306.

(12) Sabbadin, F.; Hemsworth, G. R.; Ciano, L.; Henrissat, B.; Dupree, P.; Tryfona, T.; Marques, R. D. S.; Sweeney, S. T.; Besser, K.; Elias, L.; Pesante, G.; Li, Y.; Dowle, A. A.; Bates, R.; Gomez, L. D.; Simister, R.; Davies, G. J.; Walton, P. H.; Bruce, N. C.; McQueenMason, S. J. An ancient family of lytic polysaccharide monooxygenases with roles in arthropod development and biomass digestion. Nat. Commun. 2018, 9 (1), 756.

(13) Filiatrault-Chastel, C.; Navarro, D.; Haon, M.; Grisel, S.; Herpoël-Gimbert, I.; Chevret, D.; Fanuel, M.; Henrissat, B.; HeissBlanquet, S.; Margeot, A.; Berrin, J.-G. AA16, a new lytic polysaccharide monooxygenase family identified in fungal secretomes. Biotechnol. Biofuels 2019, 12, 55.

(14) Cantarel, B. L.; Coutinho, P. M.; Rancurel, C.; Bernard, T.; Lombard, V.; Henrissat, B. The Carbohydrate-Active EnZymes database (CAZy): an expert resource for glycogenomics. Nucleic Acids Res. 2009, 37, D233-D238.

(15) Vaaje-Kolstad, G.; Forsberg, Z.; Loose, J. S. M.; Bissaro, B.; Eijsink, V. G. H. Structural diversity of lytic polysaccharide monooxygenases. Curr. Opin. Struct. Biol. 2017, 44, 67-76.

(16) Mann, S. I.; Heinisch, T.; Ward, T. R.; Borovik, A. S. Peroxide Activation Regulated by Hydrogen Bonds within Artificial $\mathrm{Cu}$ Proteins. J. Am. Chem. Soc. 2017, 139 (48), 17289-17292.

(17) Harris, P. V.; Welner, D.; McFarland, K. C.; Re, E.; Navarro Poulsen, J.-C.; Brown, K.; Salbo, R.; Ding, H.; Vlasenko, E.; Merino, S.; Xu, F.; Cherry, J.; Larsen, S.; Lo Leggio, L. Stimulation of Lignocellulosic Biomass Hydrolysis by Proteins of Glycoside Hydrolase Family 61: Structure and Function of a Large, Enigmatic Family. Biochemistry 2010, 49 (15), 3305-3316.

(18) (a) Loose, J. S. M.; Arntzen, M. Ø.; Bissaro, B.; Ludwig, R.; Eijsink, V. G. H.; Vaaje-Kolstad, G. Multipoint Precision Binding of 
Substrate Protects Lytic Polysaccharide Monooxygenases from SelfDestructive Off-Pathway Processes. Biochemistry 2018, 57 (28), 4114-4124. (b) Hemsworth, G. R.; Taylor, E. J.; Kim, R. Q.; Gregory, R. C.; Lewis, S. J.; Turkenburg, J. P.; Parkin, A.; Davies, G. J.; Walton, P. H. The copper active site of CBM33 polysaccharide oxygenases. J. Am. Chem. Soc. 2013, 135 (16), 6069-6077.

(19) Lucarini, M.; Pedrielli, P.; Pedulli, G. F.; Cabiddu, S.; Fattuoni, C. Bond Dissociation Energies of O-H Bonds in Substituted Phenols from Equilibration Studies. J. Org. Chem. 1996, 61 (26), 9259-9263.

(20) Beeson, W. T.; Vu, V. V.; Span, E. A.; Phillips, C. M.; Marletta, M. A. Cellulose Degradation by Polysaccharide Monooxygenases. Annu. Rev. Biochem. 2015, 84 (1), 923-946.

(21) Singh, R. K.; Blossom, B. M.; Russo, D. A.; Singh, R.; Weihe, H.; Andersen, N. H.; Tiwari, M. K.; Jensen, P. E.; Felby, C.; Bjerrum, M. J. Detection and characterization of a novel copper-dependent intermediate in a lytic polysaccharide monooxygenase. Chem. - Eur. J. 2019, DOI: 10.1002 /chem.201903562.

(22) (a) Gray, H. B.; Winkler, J. R. Hole hopping through tyrosine/ tryptophan chains protects proteins from oxidative damage. Proc. Natl. Acad. Sci. U. S. A. 2015, 112 (35), 10920-10925. (b) Rittle, J.; Green, M. T. Cytochrome P450 Compound I: Capture, Characterization, and C-H Bond Activation Kinetics. Science 2010, 330 (6006), 933937.

(23) Singh, R. K.; Blossom, B. M; Russo, D. A; Singh, R.; Weihe, H.; Andersen, N. H; Tiwari, M. K.; Jensen, P. E; Felby, C.; Bjerrum, M. J Detection and characterization of a novel copper-dependent intermediate in a lytic polysaccharide monooxygenase. Chem. - Eur. J. 2019, 610865.

(24) (a) Wang, B.; Johnston, E. M.; Li, P.; Shaik, S.; Davies, G. J.; Walton, P. H.; Rovira, C. QM/MM Studies into the $\mathrm{H}_{2} \mathrm{O}_{2}$-Dependent Activity of Lytic Polysaccharide Monooxygenases: Evidence for the Formation of a Caged Hydroxyl Radical Intermediate. ACS Catal. 2018, 8 (2), 1346-1351. (b) Bertini, L.; Breglia, R.; Lambrughi, M.; Fantucci, P.; De Gioia, L.; Borsari, M.; Sola, M.; Bortolotti, C. A.; Bruschi, M. Catalytic Mechanism of Fungal Lytic Polysaccharide Monooxygenases Investigated by First-Principles Calculations. Inorg. Chem. 2018, 57 (1), 86-97. (c) Wang, B.; Walton, P. H.; Rovira, C. Molecular Mechanisms of Oxygen Activation and Hydrogen Peroxide Formation in Lytic Polysaccharide Monooxygenases. ACS Catal. 2019, 9 (6), 4958-4969.

(25) Simmons, T. J.; Frandsen, K. E. H.; Ciano, L.; Tryfona, T.; Lenfant, N.; Poulsen, J. C.; Wilson, L. F. L.; Tandrup, T.; Tovborg, M.; Schnorr, K.; Johansen, K. S.; Henrissat, B.; Walton, P. H.; Lo Leggio, L.; Dupree, P. Structural and electronic determinants of lytic polysaccharide monooxygenase reactivity on polysaccharide substrates. Nat. Commun. 2017, 8 (1), 1064.

(26) Lee, Y. K.; Whittaker, M. M.; Whittaker, J. W. The electronic structure of the Cys-Tyr(center dot) free radical in galactose oxidase determined by EPR spectroscopy. Biochemistry 2008, 47 (25), 66376649.

(27) Li, X.; Beeson, W. T.; Phillips, C. M.; Marletta, M. A.; Cate, J. H.D. Structural Basis for Substrate Targeting and Catalysis by Fungal Polysaccharide Monooxygenases. Structure 2012, 20 (6), 1051-1061.

(28) Kuusk, S.; Bissaro, B.; Kuusk, P.; Forsberg, Z.; Eijsink, V. G. H.; Sørlie, M.; Väljamäe, P. Kinetics of $\mathrm{H}_{2} \mathrm{O}_{2}$-driven degradation of chitin by a bacterial lytic polysaccharide monooxygenase. J. Biol. Chem. 2018, 293 (2), 523-531.

(29) Hemsworth, G. R.; Ciano, L.; Davies, G. J.; Walton, P. H. Production and spectroscopic characterization of lytic polysaccharide monooxygenases. In Methods in Enzymology; Armstrong, F., Ed.; Academic Press, 2018; Vol. 613, Chapter 3, pp 63-90.

(30) Kjaergaard, C. H.; Qayyum, M. F.; Wong, S. D.; Xu, F.; Hemsworth, G. R.; Walton, D. J.; Young, N. A.; Davies, G. J.; Walton, P. H.; Johansen, K. S.; Hodgson, K. O.; Hedman, B.; Solomon, E. I. Spectroscopic and computational insight into the activation of $\mathrm{O}_{2}$ by the mononuclear $\mathrm{Cu}$ center in polysaccharide monooxygenases. Proc. Natl. Acad. Sci. U. S. A. 2014, 111 (24), 8797-8802.

(31) Kittl, R.; Kracher, D.; Burgstaller, D.; Haltrich, D.; Ludwig, R. Production of four Neurospora crassa lytic polysaccharide mono- oxygenases in Pichia pastoris monitored by a fluorimetric assay. Biotechnol. Biofuels 2012, 5 (1), 79.

(32) Bhattacharjee, S.; Deterding, L. J.; Jiang, J.; Bonini, M. G.; Tomer, K. B.; Ramirez, D. C.; Mason, R. P. Electron Transfer between a Tyrosyl Radical and a Cysteine Residue in Hemoproteins: Spin Trapping Analysis. J. Am. Chem. Soc. 2007, 129 (44), 1349313501.

(33) Kathiresan, M.; English, A. M. LC-MS/MS suggests that hole hopping in cytochrome $\mathrm{c}$ peroxidase protects its heme from oxidative modification by excess $\mathrm{H}_{2} \mathrm{O}_{2}$. Chem. Sci. 2017, 8 (2), 1152-1162.

(34) Solomon, E. I.; Heppner, D. E.; Johnston, E. M.; Ginsbach, J. W.; Cirera, J.; Qayyum, M.; Kieber-Emmons, M. T.; Kjaergaard, C. H.; Hadt, R. G.; Tian, L. Copper Active Sites in Biology. Chem. Rev. 2014, 114 (7), 3659-3853.

(35) Kau, L. S.; Spira-Solomon, D. J.; Penner-Hahn, J. E.; Hodgson, K. O.; Solomon, E. I. X-ray absorption edge determination of the oxidation state and coordination number of copper. Application to the type 3 site in Rhus vernicifera laccase and its reaction with oxygen. $J$. Am. Chem. Soc. 1987, 109 (21), 6433-6442.

(36) Gudmundsson, M.; Kim, S.; Wu, M.; Ishida, T.; Momeni, M. H.; Vaaje-Kolstad, G.; Lundberg, D.; Royant, A.; Ståhlberg, J.; Eijsink, V. G. H.; Beckham, G. T.; Sandgren, M. Structural and Electronic Snapshots during the Transition from a $\mathrm{Cu}$ (II) to $\mathrm{Cu}(\mathrm{I})$ Metal Center of a Lytic Polysaccharide Monooxygenase by X-ray Photoreduction. J. Biol. Chem. 2014, 289 (27), 18782-18792.

(37) Borfecchia, E.; Lomachenko, K. A.; Giordanino, F.; Falsig, H.; Beato, P.; Soldatov, A. V.; Bordiga, S.; Lamberti, C. Revisiting the nature of $\mathrm{Cu}$ sites in the activated Cu-SSZ-13 catalyst for SCR reaction. Chem. Sci. 2015, 6 (1), 548-563.

(38) Shadle, S. E.; Pennerhahn, J. E.; Schugar, H. J.; Hedman, B.; Hodgson, K. O.; Solomon, E. I. X-Ray Absorption Spectroscopic Studies of the Blue Copper Site - Metal and Ligand K-Edge Studies to Probe the Origin of the Epr Hyperfine Splitting in Plastocyanin. J. Am. Chem. Soc. 1993, 115 (2), 767-776.

(39) Walroth, R. C.; Miles, K. C.; Lukens, J. T.; MacMillan, S. N.; Stahl, S. S.; Lancaster, K. M. Electronic Structural Analysis of Copper(II)-TEMPO/ABNO Complexes Provides Evidence for Copper(I)-Oxoammonium Character. J. Am. Chem. Soc. 2017, 139 (38), 13507-13517.

(40) Lim, H.; Thomas, K. E.; Hedman, B.; Hodgson, K. O.; Ghosh, A.; Solomon, E. I. X-ray Absorption Spectroscopy as a Probe of Ligand Noninnocence in Metallocorroles: The Case of Copper Corroles. Inorg. Chem. 2019, 58 (10), 6722-6730.

(41) McGlashen, M. L.; Eads, D. D.; Spiro, T. G.; Whittaker, J. W. Resonance Raman Spectroscopy of Galactose Oxidase: A New Interpretation Based on Model Compound Free Radical Spectra. J. Phys. Chem. 1995, 99 (14), 4918-4922.

(42) Cappuccio, J. A.; Ayala, I.; Elliott, G. I.; Szundi, I.; Lewis, J.; Konopelski, J. P.; Barry, B. A.; Einarsdóttir, Ó. Modeling the Active Site of Cytochrome Oxidase: Synthesis and Characterization of a Cross-Linked Histidine-Phenol. J. Am. Chem. Soc. 2002, 124 (8), $1750-1760$.

(43) Wang, Y.; DuBois, J. L.; Hedman, B.; Hodgson, K. O.; Stack, T. D. P. Catalytic Galactose Oxidase Models: Biomimetic $\mathrm{Cu}(\mathrm{II})$ Phenoxyl-Radical Reactivity. Science 1998, 279 (5350), 537-540.

(44) Roemelt, M.; Beckwith, M. A.; Duboc, C.; Collomb, M.-N.; Neese, F.; DeBeer, S. Manganese K-Edge X-Ray Absorption Spectroscopy as a Probe of the Metal-Ligand Interactions in Coordination Compounds. Inorg. Chem. 2012, 51 (1), 680-687.

(45) Verma, P.; Weir, J.; Mirica, L.; Stack, T. D. P. Tale of a Twist: Magnetic and Optical Switching in Copper(II) Semiquinone Complexes. Inorg. Chem. 2011, 50 (20), 9816-9825.

(46) Müller, J.; Weyhermüller, T.; Bill, E.; Hildebrandt, P.; OuldMoussa, L.; Glaser, T.; Wieghardt, K. Why Does the Active Form of Galactose Oxidase Possess a Diamagnetic Ground State? Angew. Chem., Int. Ed. 1998, 37 (5), 616-619.

(47) Clark, K.; Penner-Hahn, J. E.; Whittaker, M. M.; Whittaker, J. $\mathrm{W}$. Oxidation-state assignments for galactose oxidase complexes from 
$\mathrm{x}$-ray absorption spectroscopy. Evidence for copper(II) in the active enzyme. J. Am. Chem. Soc. 1990, 112 (17), 6433-6434.

(48) Hangasky, J. A.; Iavarone, A. T.; Marletta, M. A. Reactivity of $\mathrm{O}_{2}$ versus $\mathrm{H}_{2} \mathrm{O}_{2}$ with polysaccharide monooxygenases. Proc. Natl. Acad. Sci. U. S. A. 2018, 115 (19), 4915-4920.

(49) Warren, J. J.; Winkler, J. R.; Gray, H. B. Redox properties of tyrosine and related molecules. FEBS Lett. 2012, 586 (5), 596-602.

(50) Teo, R. D.; Rousseau, B. J. G.; Smithwick, E. R.; Di Felice, R.; Beratan, D. N.; Migliore, A. Charge Transfer between [4Fe4S] Proteins and DNA Is Unidirectional: Implications for Biomolecular Signaling. Chem. 2019, 5 (1), 122-137.

(51) Hopfield, J. J. Electron Transfer Between Biological Molecules by Thermally Activated Tunneling. Proc. Natl. Acad. Sci. U. S. A. 1974, 71 (9), 3640-3644.

(52) Teo, R. D.; Wang, R.; Smithwick, E. R.; Migliore, A.; Therien, M. J.; Beratan, D. N. Mapping hole hopping escape routes in proteins. Proc. Natl. Acad. Sci. U. S. A. 2019, 116 (32), 15811-15816.

(53) Harriman, A. Further comments on the redox potentials of tryptophan and tyrosine. J. Phys. Chem. 1987, 91 (24), 6102-6104.

(54) (a) Kuusk, S.; Kont, R.; Kuusk, P.; Heering, A.; Sørlie, M.; Bissaro, B.; Eijsink, V. G. H.; Väljamäe, P. Kinetic insights into the role of the reductant in $\mathrm{H}_{2} \mathrm{O}_{2}$-driven degradation of chitin by a bacterial lytic polysaccharide monooxygenase. J. Biol. Chem. 2019, 294 (5), 1516-1528. (b) Chalak, A.; Villares, A.; Moreau, C.; Haon, M.; Grisel, S.; d'Orlando, A.; Herpoël-Gimbert, I.; Labourel, A.; Cathala, B.; Berrin, J.-G. Influence of the carbohydrate-binding module on the activity of a fungal AA9 lytic polysaccharide monooxygenase on cellulosic substrates. Biotechnol. Biofuels 2019, 12 (1), 206.

(55) Neese, F. Software update: the ORCA program system, version 4.0. WIREs Comput. Mol. Sci. 2018, 8 (1), e1327.

(56) Becke, A. D. Density-functional exchange-energy approximation with correct asymptotic behavior. Phys. Rev. A: At., Mol., Opt. Phys. 1988, 38 (6), 3098-3100.

(57) Weigend, F.; Ahlrichs, R. Balanced basis sets of split valence, triple zeta valence and quadruple zeta valence quality for $\mathrm{H}$ to $\mathrm{Rn}$ : Design and assessment of accuracy. Phys. Chem. Chem. Phys. 2005, 7 (18), 3297-3305.

(58) Grimme, S.; Ehrlich, S.; Goerigk, L. Effect of the damping function in dispersion corrected density functional theory. J. Comput. Chem. 2011, 32 (7), 1456-1465.

(59) Becke, A. D. Density-functional thermochemistry. III. The role of exact exchange. J. Chem. Phys. 1993, 98 (7), 5648-5652.

(60) Soda, T.; Kitagawa, Y.; Onishi, T.; Takano, Y.; Shigeta, Y.; Nagao, H.; Yoshioka, Y.; Yamaguchi, K. Ab initio computations of effective exchange integrals for $\mathrm{H}-\mathrm{H}, \mathrm{H}-\mathrm{He}-\mathrm{H}$ and $\mathrm{Mn}_{2} \mathrm{O}_{2}$ complex: comparison of broken-symmetry approaches. Chem. Phys. Lett. 2000, 319 (3), 223-230.

(61) Hirata, S.; Head-Gordon, M. Time-dependent density functional theory within the Tamm-Dancoff approximation. Chem. Phys. Lett. 1999, 314 (3), 291-299.

(62) Neese, F.; Wennmohs, F.; Hansen, A.; Becker, U. Efficient, approximate and parallel Hartree-Fock and hybrid DFT calculations. A 'chain-of-spheres' algorithm for the Hartree-Fock exchange. Chem. Phys. 2009, 356 (1), 98-109.

(63) van Wüllen, C. Molecular density functional calculations in the regular relativistic approximation: Method, application to coinage metal diatomics, hydrides, fluorides and chlorides, and comparison with first-order relativistic calculations. J. Chem. Phys. 1998, 109 (2), 392-399.

(64) Neese, F. Prediction and interpretation of the 57Fe isomer shift in Mössbauer spectra by density functional theory. Inorg. Chim. Acta 2002, 337, 181-192.

(65) Pantazis, D. A.; Chen, X.-Y.; Landis, C. R.; Neese, F. AllElectron Scalar Relativistic Basis Sets for Third-Row Transition Metal Atoms. J. Chem. Theory Comput. 2008, 4 (6), 908-919.

(66) DeBeer George, S.; Petrenko, T.; Neese, F. Prediction of Iron K-Edge Absorption Spectra Using Time-Dependent Density Functional Theory. J. Phys. Chem. A 2008, 112 (50), 12936-12943. 